\title{
RESEARCH
}

Open Access

\section{TRPC7 regulates the electrophysiological functions of embryonic stem cell-derived cardiomyocytes}

\author{
Xianji Liu', Rui Zhao', Qianqian Ding ${ }^{1}$, Xiaoqiang Yao ${ }^{2}$ and Suk Ying Tsang ${ }^{1,3,4,5^{*}}$ (D
}

\begin{abstract}
Background: Biological pacemakers consisting of pluripotent stem cell-derived cardiomyocytes are potentially useful for treating bradycardia. However, tachyarrhythmia caused by derived cardiomyocytes themselves is one of main barriers hampering their clinical translation. An in-depth understanding of the mechanisms underlying the spontaneous action potential (a.k.a. automaticity) might provide potential approaches to solve this problem. The aim of this project is to study the role of canonical transient receptor potential isoform 7 (TRPC7) channels in regulating the automaticity of embryonic stem cell-derived cardiomyocytes (ESC-CMs).
\end{abstract}

Methods and results: By Western blotting, the expression of TRPC7 was found to be increased during the differentiation of mouse ESC-CMs (mESC-CMs). Adenovirus-mediated TRPC7 knockdown decreased while overexpression increased the frequency of $\mathrm{Ca}^{2+}$ transients (CaTs), local $\mathrm{Ca}^{2+}$ releases (LCRs), and action potentials (APs) as detected by confocal microscopy and whole-cell patch-clamping. TRPC7 was found to be positively associated with the activity of ryanodine receptor 2 (RyR2), sarco/endoplasmic reticulum $\mathrm{Ca}^{2+}$-ATPase (SERCA), and sodium-calcium exchanger (NCX) but not hyperpolarization-activated, cyclic nucleotide-gated channel (HCN), and inositol trisphosphate receptor (IP3R). Knockdown or overexpression of TRPC7 did not alter the expression of HCN4, Cav1.3, Cav3.1, Cav3.2, IP3R1, RyR2, and SERCA but positively regulated the phosphorylation of RyR2 at S2814 and phospholamban (PLN) at T17. Moreover, the positive regulation of APs by TRPC7 was $\mathrm{Ca}^{2+}$-dependent, as overexpression of N-terminus of TRPC7 (dominant negative of TRPC7) which diminished the $\mathrm{Ca}^{2+}$ permeability of TRPC7 decreased the AP frequency.

Conclusions: TRPC7 regulates the automaticity of mESC-CMs through two mechanisms. On the one hand, TRPC7 positively regulates the intracellular $\mathrm{Ca}^{2+}$ clock through the regulation of activities of both RyR2 and SERCA; on the other hand, TRPC7 also positively regulates the membrane clock via its influence on NCX activity. Altogether, our study reveals that TRPC7 is a potential drug target to manipulate the action potential firing rate of pluripotent stem cellderived cardiomyocyte-based biological pacemakers to prevent tachyarrhythmia, a condition that might be encountered after transplantation.

Keywords: Embryonic stem cells, Cardiomyocytes, Canonical transient receptor potential isoform 7 channel, Electrophysiology

\footnotetext{
* Correspondence: fayetsang@cuhk.edu.hk

'School of Life Sciences, The Chinese University of Hong Kong, Hong Kong

SAR, China

${ }^{3}$ State Key Laboratory of Agrobiotechnology, The Chinese University of Hong

Kong, Hong Kong SAR, China

Full list of author information is available at the end of the article
}

\section{$\triangle B M C$}

(c) The Author(s). 2021 Open Access This article is licensed under a Creative Commons Attribution 4.0 International License, which permits use, sharing, adaptation, distribution and reproduction in any medium or format, as long as you give appropriate credit to the original author(s) and the source, provide a link to the Creative Commons licence, and indicate if changes were made. The images or other third party material in this article are included in the article's Creative Commons licence, unless indicated otherwise in a credit line to the material. If material is not included in the article's Creative Commons licence and your intended use is not permitted by statutory regulation or exceeds the permitted use, you will need to obtain permission directly from the copyright holder. To view a copy of this licence, visit http://creativecommons.org/licenses/by/4.0/ The Creative Commons Public Domain Dedication waiver (http://creativecommons.org/publicdomain/zero/1.0/) applies to the data made available in this article, unless otherwise stated in a credit line to the data. 


\section{Background}

Electronic pacing is a prevalent therapy to treat patients with symptomatic bradycardia or high-grade atrioventricular block. The world-wide survey suggested that around a million electronic pacemakers were transplanted in 2009 [1], and this number kept rising due to the aging population and the increasing number of patients with heart diseases [2, 3]. Despite their proven efficacy, electronic pacemakers still have some drawbacks, including limited battery life, device infections, lack of responsiveness to the autonomic nerves, and high magnetic fields incompatibility [4]. Therefore, the demand for developing better treatments is always existing. Benefiting from the fast development in the field of regenerative medicine, biological pacemakers which consist of cardiomyocytes derived from pluripotent stem cells (PSCs) have brought patients a promising adjunct or alternative therapy. Although proof-of-concept studies have demonstrated the potential of biological pacemakers to restore the heart rhythm in animal experiments, several safety concerns are still existing and hampering their clinical translation [5]. One of such concerns is tachyarrhythmia caused by the transplantation of PSC-derived cardiomyocytes because of their enhanced automaticity [6].

A crucial mechanism underlying the automaticity is the spontaneous occurrence of depolarization in the phase 4 of action potentials (APs). This spontaneous depolarization is determined by the ensemble of ion channels and exchangers on the plasma membrane which is defined as the membrane clock and rhythmic $\mathrm{Ca}^{2+}$ released from the sarcoplasmic reticulum (SR) which is regarded as the intracellular $\mathrm{Ca}^{2+}$ clock [7-9]. Inward funny current $\left(I_{\mathrm{f}}\right)$ carried by hyperpolarizationactivated cyclic nucleotide-gated (HCN) channels contributes to the early diastolic depolarization (DD) $[10,11]$. During the mid and late DD, $\mathrm{Na}^{+}-\mathrm{Ca}^{2+}$ exchanger (NCX) generates an increasing inward current which leads to the acceleration of the late DD [12-14]. On the other hand, intracellular local $\mathrm{Ca}^{2+}$ releases (LCRs; also known as $\mathrm{Ca}^{2+}$ sparks) mediated by ryanodine receptor 2 (RyR2) occur spontaneously during the mid and late phase 4 and tick the time of $\mathrm{Ca}^{2+}$ clock. Because of the spatial proximity between SR and plasma membrane, $\mathrm{Ca}^{2+}$ released from RyR2 is moved out of the cell by NCX and this generates an inward current to accelerate late DD $[12,15]$. By this way, the membrane clock and $\mathrm{Ca}^{2+}$ clock couple to each other to manipulate the spontaneous DD.

Although determinant proteins implicated in the automaticity have been well elucidated, the process is highly complicated, and more importantly, to ensure both robustness and elasticity of the automaticity, redundant mechanisms may exist for the regulation. Canonical transient receptor potential isoform 7 (TRPC7) is a non- selective cation channel with a higher selectivity of divalent cations over monovalent cations [16]. TRPC7 has been demonstrated to be a receptor-operated $\mathrm{Ca}^{2+}$ channel (ROCC). Specifically, G protein-coupled receptors (GPCRs) locating on the plasma membrane sense the external stimuli such as hormones, neurotransmitters, and growth factors transduce the signal to activate phospholipase C (PLC) which hydrolyzes the phosphatidylinositol 4,5-bisphosphate (PIP2) into inositol 1,4, 5-trisphosphate (IP3) and diacylglycerol (DAG). TRPC7 is then directly activated by DAG, mediating the $\mathrm{Ca}^{2+}$ influx $[17,18]$.

In adult rat ventricular myocytes, TRPC3/7 heterotetramers were found to mediate an inward depolarization current and trigger arrythmia under the stimulation of ATP/UTP which is released in early infarct [19]. In neonatal rat ventricular myocytes (NRVMs), overexpression of TRPC7 was shown to induce apoptosis without/with angiotensin II stimulation probably through the calcineurin-dependent pathway, which may underlie the hypertension-induced heart failure [20]. Although these studies implied the potential functions of TRPC7 in the pathophysiology of cardiac diseases, the detailed mechanisms through which TRPC7 leads to the diseases are still elusive, mainly due to the absence of specific pharmacological agonists/antagonists and inhibitory antibodies of this channel. Moreover, both studies focused on functions of TRPC7 under pathological conditions, leaving its potential impacts on automaticity under normal physiological conditions unexplored. In light of the fact that TRPC7 relatives, including TRPM4 [21, 22], TRPM7 [23], and TRPC3 [24, 25], have been demonstrated to modulate the automaticity of cardiomyocytes, the aim of the present study was to investigate the role of TRPC7 in regulating the automaticity of developing cardiomyocytes using mouse embryonic stem cell-derived cardiomyocytes (mESC-CMs) which have been shown to generate sinoatrial nodal-like spontaneous APs [26, 27]. This study may help to further elaborate the mechanism underlying the automaticity of PSC-derived cardiomyocytes and provide some insights into potential solutions to conquer tachyarrhythmia caused by the transplantation of these cells.

\section{Materials and methods}

\section{mESC culture and mESC-CM differentiation}

mESCs from D3 line (ATCC, Manassas, VA, USA) were cultured as previously described [25, 28-30]. Briefly, mESCs were grown on Gamma-ray-irradiated mouse embryonic fibroblasts (MEFs), with Dulbecco's modified Eagle's medium (DMEM) (Invitrogen, Carlsbad, CA, USA) containing $15 \%$ heat-inactivated fetal bovine serum (FBS) (Hyclone, GE Healthcare, South Logan, UT, USA), $2 \mathrm{mM}$ L-glutamine (Invitrogen), $0.1 \mathrm{mM}$ non-essential amino 
acids (NEAA) (Invitrogen), 1\% v/v penicillin-streptomycin (Invitrogen), $0.1 \mathrm{mM} \beta$-mercaptoethanol (Invitrogen), and $1000 \mathrm{U} / \mathrm{mL}$ leukemia inhibitory factor (LIF) (Chemicon, Millipore, Billerica, MA, USA) to maintain the undifferentiated status of mESCs. The medium was changed every day and the cells were passaged every other day. Differentiation was conducted through embryoid body (EB) method. Briefly, on day 0, cells were dissociated with $0.05 \%$ trypsin (Invitrogen) and resuspended in the medium without LIF. The cells were plated on a dish pre-coated with $0.1 \%$ gelatin (Sigma, St. Louis, Missouri, USA) and placed in the incubator for $30 \mathrm{~min}$, allowing separation of mESCs from MEFs. mESCs suspending in the medium were collected and made into hanging drops, with each drop containing $20 \mu \mathrm{L}$ medium and 800 mESCs. EBs were washed down to Petri dishes on day 2, maintained in suspension in $10 \mathrm{~mL}$ medium. On day 7, EBs were attached to dishes pre-coated with $0.1 \%$ gelatin and checked daily for the appearance of beating phenotypes.

\section{Isolation of $\mathrm{mESC}-\mathrm{CMs}$}

Isolation of mESC-CMs was performed as previously described [25, 30]. Briefly, beating regions of EBs were dissected out and minced into small pieces with a $27-\mathrm{G}$ needle under a dissection microscope. The EB pieces were centrifuged at $1000 \times g$ to remove medium and washed with pre-chilled PBS, then dissociated with $1 \mathrm{mg} /$ $\mathrm{mL}$ collagenase B (Roche Diagnostics, Basel, Switzerland) in NB buffer containing $120 \mathrm{mM} \mathrm{NaCl}, 5.4 \mathrm{mM} \mathrm{KCl}, 5$ $\mathrm{mM} \mathrm{MgSO}_{4}, 5 \mathrm{mM}$ Na pyruvate, $20 \mathrm{mM}$ glucose, $20 \mathrm{mM}$ taurine, $10 \mathrm{mM}$ HEPES, and $30 \mu \mathrm{MCaCl}_{2}$, and $\mathrm{pH}$ was adjusted to 6.9 by $\mathrm{NaOH}$. Dissociation was conducted at $37^{\circ} \mathrm{C}$ for 20 min with gentle shaking. Collagenase $\mathrm{B}$ was then removed by centrifugation at $1000 \times g$ and $1 \mathrm{~mL} \mathrm{~KB}$ buffer was added to resuspend the cells. $\mathrm{KB}$ buffer was made of $85 \mathrm{mM} \mathrm{KCl}, 30 \mathrm{mM} \mathrm{K}_{2} \mathrm{HPO}_{4}, 5 \mathrm{mM} \mathrm{MgSO}_{4}, 1$ $\mathrm{mM}$ EGTA, $5 \mathrm{mM}$ pyruvic acid, $5 \mathrm{mM}$ creatine, $20 \mathrm{mM}$ taurine, $20 \mathrm{mM}$ glucose, and $87 \mu \mathrm{M}$ of Na-ATP (Sigma), and $\mathrm{pH}$ was adjusted to 7.2 by $\mathrm{NaOH}$. The cells were further dissociated by gentle pipetting. Thereafter, they were plated on glass coverslips or confocal dishes for further use.

\section{Isolation of neonatal rat ventricular myocytes (NRVMs)}

This study was approved by the Animal Experimentation Ethics Committee, the Chinese University of Hong Kong (17-006-MIS) and conformed to Guide for the Care and Use of Laboratory Animals published by the US National Institutes of Health (NIH Publication No. 80-23, revised 2011). Neonatal male rat pups (1-2 days postnatal) were sacrificed and the hearts were cut out. Atria were removed and ventricles of were cut into small pieces and washed in pre-chilled PBS on ice to remove blood. Ventricles were digested using $0.5 \mathrm{mg} / \mathrm{mL}$ collagenase type II
(17101015, Gibco, Thermo) with gentle agitation. The digestion was ceased by adding DF-20 medium containing DMEM/F12 medium (11320033, Gibco, Thermo) and 20\% FBS (Gibco, Thermo). Dissociated NRVMs were centrifuged at $1500 \mathrm{rpm}, 4{ }^{\circ} \mathrm{C}$ for $10 \mathrm{~min}$. The supernatant was discarded, and the cells were resuspended into plating medium containing DMEM/F12 medium, 5\% FBS, 10\% horse serum (26050088, Gibco, Thermo), and $1 \% \mathrm{v} / \mathrm{v}$ penicillin-streptomycin. The cells were plated to dishes or glass slides for further experiments.

\section{Molecular cloning}

Mouse TRPC7 cDNA [16] was kindly provided by Professor Yasuo Mori (Kyoto University). For constructing TRPC7 overexpression plasmid Blue-pAdTrack-CMVTRPC7, restriction endonuclease sites KpnI and NotI were added to $5^{\prime}$ - and $3^{\prime}$ - end of mTRPC7 cDNA, respectively, by PCR and the cDNA was ligated into the adenoviral shuttle plasmid Blue-pAdTrack-CMV which was modified from pAdTrack-CMV plasmid (Addgene plasmid \# 16405). For constructing Tag-TRPC7 overexpression plasmid Blue-pAdTrack-CMV-TagTRPC7 KpnI site plus 3× Flag was added to the $5^{\prime}$ - end, $3 \times$ hemagglutinin (HA) plus NotI site was added to the $3^{\prime}$ - end of mTRPC7 cDNA, the cDNA was then ligated into Blue-pAdTrackCMV. For constructing TRPC7 knockdown plasmids pAdTrack-U6-shRNA458 and pAdTrack-U6-shRNA459, two sequences of shRNA, shRNA-458 (targeting mouse TRPC7) and shRNA-459 (targeting rat TRPC7), adopted from Genetic Perturbation Platform were synthesized and ligated into the adenoviral shuttle plasmid pAdTrack-U6 at AgeI and XhoI restriction sites. pAdTrack-U6 was modified from pAdTrack plasmid (Addgene plasmid \# 16404). The plasmid pAdTrack-U6-shRNAluc harboring shRNA targeting luciferase (shRNA-luc) was constructed as a negative control [31]. Targeting sequences of these shRNAs were shRNA-458: 5'-GCCGAATCAAACTCGC CATTA-3', shRNA-459: 5' -GCCAACATTGAGAC TGAATTT-3', shRNA-luc: 5'-CCTAAGGTTAAGTCGC CCTCG-3'.

\section{Adenovirus production and infection}

Adenovirus was prepared using AdEasy Adenoviral Vector System Kit (Agilent Technologies, Santa Clare, CA, USA) according to the manufacturer's protocol. Briefly, the resultant adenoviral shuttle plasmids with gene-of-interest were linearized by the digestion of PmeI. The linearized shuttle plasmids were co-transformed with adenoviral backbone plasmid into E. coli BJ5183 cells by electroporation. The bacteria were spread onto kanamycincontaining agarose plates to grow for $24 \mathrm{~h}$. Candidate recombinants which were the smallest colonies on the plates were picked and shaken in $5 \mathrm{~mL}$ kanamycin- 
containing LB medium for $16 \mathrm{~h}$. Plasmids were extracted, and PCR and diagnostic restriction digestion were used to screen for the positive recombinants. Validated plasmids were transformed into $E$. coli $\mathrm{DH} 5 \alpha$ cells for a further amplification. Finally, the recombinant plasmids were digested with PacI and transfected into HEK-293-AD cells with Lipofectamine 2000 (Invitrogen). Ten days after transfection, the cells were collected to extract adenoviruses by repeated freeze-and-thaw cycles. The viruses were further amplified in HEK-293-AD cells to gain a higher titration. For infection, viruses at 1 multiplicity of infection (MOI) were used for a moderate overexpression, and viruses at $20 \mathrm{MOI}$ were used for a full knockdown. mESC-CMs or NRVMs were infected with viruses for $6 \mathrm{~h}$ in normal medium. Assays for overexpression were conducted 2 days after infection, and assays for knockdown were conducted 4 or 8 days after infection.

\section{Confocal $\mathrm{Ca}^{2+}$ imaging}

Isolated mESC-CMs on confocal dishes were stained with $1 \mu \mathrm{M}$ rhod-2 AM (Invitrogen) for $15 \mathrm{~min}$ in medium, then washed with pre-warmed Tyrode's solution containing $1 \mathrm{mM} \mathrm{MgCl} 2,1.8 \mathrm{mM} \mathrm{CaCl}_{2}, 5.4 \mathrm{mM}$ $\mathrm{KCl}, 10 \mathrm{mM}$ glucose, $10 \mathrm{mM}$ HEPES, and $140 \mathrm{mM} \mathrm{NaCl}$, pH 7.2 (adjusted by $\mathrm{NaOH}$ ). The cells were bathed in Tyrode's solution. Leica SP8 confocal microscope equipped with $552 \mathrm{~nm}$ laser and $\times 63$ oil immersion objective was used for $\mathrm{Ca}^{2+}$ imaging. For the $\mathrm{Ca}^{2+}$ transients (CaTs) recording, the XYT mode was adopted. Images with a size of $16 \times 16$ pixels were captured in a frequency of $50 \mathrm{~Hz}$ for $1 \mathrm{~min}$ for each beating mESC$\mathrm{CM}$. For the LCRs recording, a XT line-scanning mode was used. A line in a length of 512 pixels was used to scan each beating cell in a frequency of $600 \mathrm{~Hz}$ for $13 \mathrm{~s}$. ImageJ (NIH, Bethesda, MD, USA) was used to analyze the signal from CaTs images, a customized Python script was developed to analyze the parameters of CaTs. SparkMaster (University of California, Davis, CA, USA) was used for the analysis of LCRs [32].

\section{Electrophysiology}

Membrane potential and ionic current were measured with the ruptured whole-cell patch clamp using Axopatch 200B amplifier (Molecular Devices, Sunnyvale, CA, USA) and pCLAMP 10.4 software (Molecular Devices) as previously described [25]. Signals were digitized at $10 \mathrm{kHz}$ and filtered at $2 \mathrm{kHz}$. Microelectrodes (1B150F-4, World Precision Instruments, Sarasota, FL, USA) with resistances of 3-6 M $\Omega$ were pulled from P-97 puller (Sutter Instrument, Novato, CA, USA). For the AP recording, cells were bathed in Tyrode's solution. The pipette solution was composed of $50 \mathrm{mM} \mathrm{KCl,} 80$ mM KAspartate, $1 \mathrm{mM} \mathrm{MgCl}_{2}, 3 \mathrm{mM} \mathrm{MgATP}, 10 \mathrm{mM}$ EGTA, and $10 \mathrm{mM}$ HEPES, pH 7.4 (adjusted with $\mathrm{KOH}$ ).
For NCX current $\left(I_{\mathrm{NCX}}\right)$ measurement, cells were bathed in the solution containing $140 \mathrm{mM} \mathrm{NaCl}, 1.8 \mathrm{mM} \mathrm{CaCl}_{2}$, $1.2 \mathrm{mM} \mathrm{MgCl}_{2}, 1 \mu \mathrm{M}$ nifedipine, $20 \mu \mathrm{M}$ ouabain, $1 \mu \mathrm{M}$ ryanodine, $10 \mu \mathrm{M}$ zatebradine, $5.5 \mathrm{mM}$ HEPES, and 11 $\mathrm{mM}$ glucose, $\mathrm{pH} 7.4$ (adjusted with $\mathrm{NaOH}$ ). The pipette solution was composed of $65 \mathrm{mM} \mathrm{CsCl,} 20 \mathrm{mM} \mathrm{NaCl}, 5$ $\mathrm{mM} \mathrm{Na} \mathrm{N}_{2} \mathrm{ATP}, 1.75 \mathrm{mM} \mathrm{CaCl}, 4 \mathrm{mM} \mathrm{MgCl}_{2}, 10 \mathrm{mM}$ HEPES, $20 \mathrm{mM}$ tetraethylammonium chloride, and 5 mM EGTA, pH 7.2 (adjusted with $\mathrm{CsOH}$ ). The following ramp-voltage-clamp protocol was used to elicit the $I_{\mathrm{NCX}}$ : the potential was held at $-40 \mathrm{mV}$, then gradually increased to $+50 \mathrm{mV}$, followed by a decline to $-100 \mathrm{mV}$, finally increased back to $+40 \mathrm{mV}$, with a ramp rate of $200 \mathrm{mV} / 500 \mathrm{~ms}$. $I_{\mathrm{NCX}}$ was indicated by the repolarization limb (from $-50 \mathrm{mV}$ to $-100 \mathrm{mV}$ ) of the protocol as documented previously $[25,33]$. For the recording of $I_{\mathrm{f}}$, cells were bathed in Tyrode solution supplied with $2 \mathrm{mM}$ $\mathrm{BaCl}_{2}$ and $2 \mathrm{mM} \mathrm{MmCl}$ to suppress $\mathrm{K}^{+}$and $\mathrm{Ca}^{2+}$ current [34]. The pipette solution contained $10 \mathrm{mM} \mathrm{NaCl}, 50 \mathrm{mM}$ $\mathrm{KCl}, 80 \mathrm{mM} \mathrm{KOH}, 1 \mathrm{mM} \mathrm{MgCl}, 10 \mathrm{mM}$ HEPES, and 3 mM MgATP, pH 7.2 (adjusted with $\mathrm{KOH}$ ). Five millimoles $\mathrm{CsCl}$ was applied to the bath solution to inhibit $I_{\mathrm{f}}$.

\section{Western blotting}

One hundred micrograms proteins were loaded to $7.5 \%$ polyacrylamide gel and transferred to $0.45 \mu \mathrm{m}$ PVDF membranes (Millipore). Membranes were blocked with $5 \%$ (w:v) milk for $1 \mathrm{~h}$ at room temperature then incubated with primary antibodies at $4{ }^{\circ} \mathrm{C}$ overnight. The membranes were washed with TBST three times and incubated with secondary antibody for $1 \mathrm{~h}$ at room temperature. Finally, the membranes were developed with Clarity Western ECL Substrate (Bio-Rad) and pictures were taken by ChemiDoc Touch (Bio-Rad). Antibodies used were anti-TRPC7 1:500 (HPA031126, Sigma), anti- $\beta$-tubulin 1:1000 (15,115, Cell Signaling, Danvers, Massachusetts, USA), anti-HCN4 1:200 (APC052, Alomone), anti-Cav1.3 1:100 (ACC-005, Alomone), anti-Cav3.1 1:200 (ACC-021, Alomone), anti-Cav3.2 1: 200 (ACC-025, Alomone), anti-RyR2 1:1000 (MA3-916, Invitrogen), anti-SERCA 1:200 (sc-30110, Santa Cruz), anti-IP3R 1:500 (ACC-019, Alomone), anti-p(S2814)RyR2 1:5000 (A010-31, Badrilla), anti-phospholamban (PLN) 1: 1000 (A010-14, Badrilla), anti-p(T17) PLN 1:5000 (A01013, Badrilla), HRP-conjugated goat anti-rabbit secondary antibody 1:5000 (Dako, Zug, Switzerland), and HRPconjugated goat anti-mouse secondary antibody 1:5000 (Dako).

\section{Drugs and chemical reagents}

Ouabain was purchased from the International Laboratory USA (South San Francisco, CA, USA). 2-2Aminoethoxydipheylborate (2-APB) and thapsigargin were purchased from Tocris (Bristol, UK). Nifedipine, 
ryanodine, zatebradine, and all chemical reagents used to setup buffer solutions were purchased from Sigma.

\section{Statistical analysis}

Three or more biological repeats were performed for each experiment. Data were presented as mean \pm SEM. Data between two groups were compared by unpaired Student's $t$-test. Data between three or more groups were compared by one-way analysis of variance (ANOVA) followed by Bonferroni's multiple comparison tests. $P<0.05$ was considered to be statistically significant.

\section{Results}

The expression of TRPC7 increased during the differentiation of $\mathrm{mESC}-\mathrm{CMs}$

To start our study, we first detected the expression of TRPC7 in mESCs at different stages during the differentiation. Cells were collected from mESCs and
EBs on day 4, 7, $7+4,7+8,7+12$, and $7+19$, respectively; total proteins were extracted and subjected to Western blotting analysis. We found that neither mESCs nor EBs before their attachment to culture dishes (on day 7) expressed TRPC7. A significant increase of TRPC7 expression was observed since day $7+8$ ( 8 days after attachment). TRPC7 expression kept rising until day $7+12$ when it reached the plateau (Fig. 1). By co-staining of TRPC7 with cardiac markers, including cTnT and $\alpha$-actinin, TRPC7 was also shown to be present in $\mathrm{mESC}-\mathrm{CMs}$ and NRVMs (Supplementary Fig. 1).

TRPC7 positively regulated the $\mathrm{Ca}^{2+}$ handling in $\mathrm{mESC}-\mathrm{CMs}$ $\mathrm{Ca}^{2+}$ is important to various bioprocesses and cellular functions. In pacemaker cells, it is the foundation of $\mathrm{Ca}^{2+}$ clock which determines the automaticity. To study the function of TRPC7 in regulating the automaticity of mESC-CMs, $\mathrm{Ca}^{2+}$ handling was first investigated.

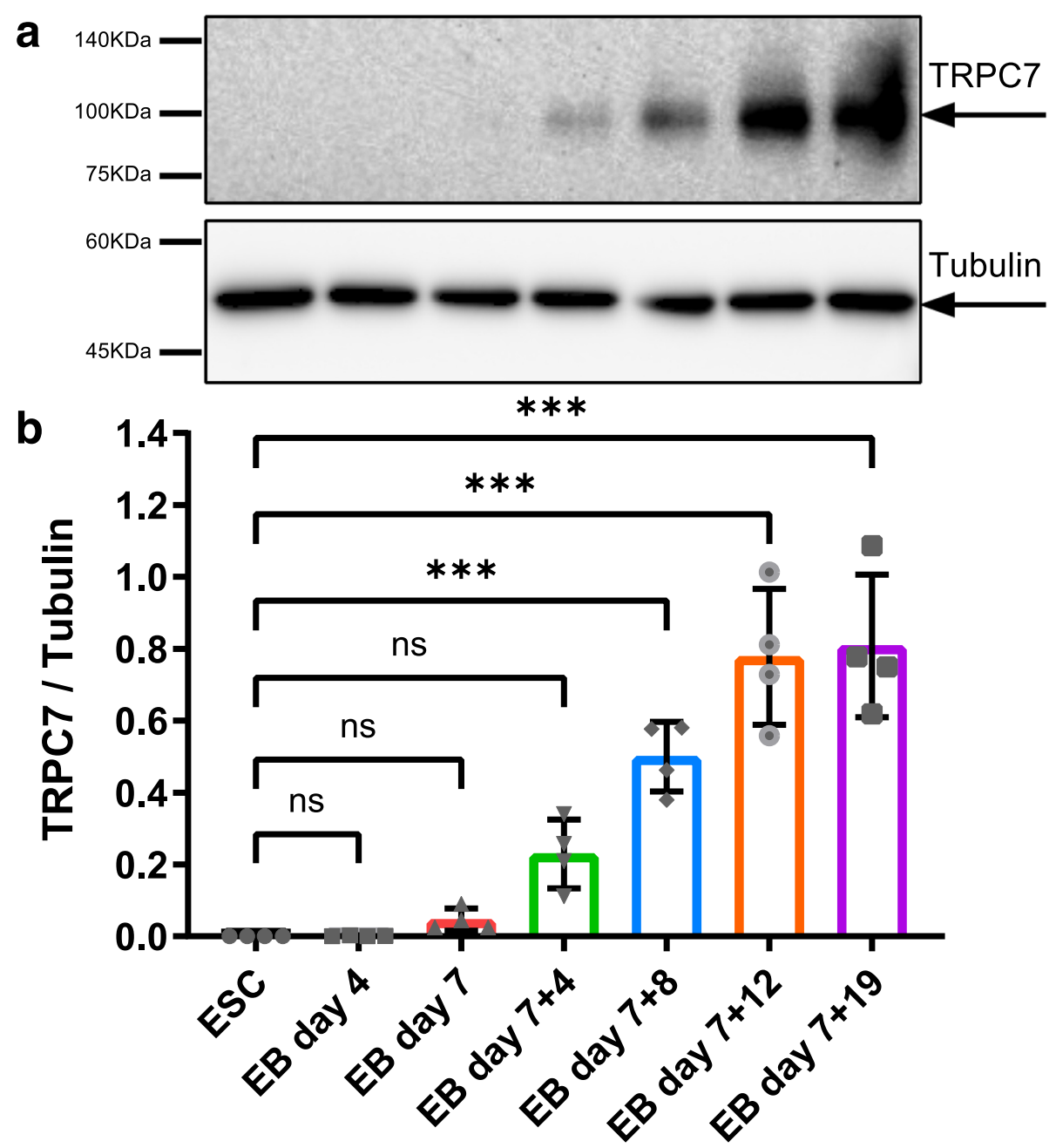

Fig. 1 The expression of TRPC7 increased during the differentiation of mESC-CMs. a Representative Western blot showing the expression of TRPC7 at different stages. $\mathbf{b}$ Bar chart showing the quantification of TRPC7 normalized to $\beta$-tubulin. Data were presented as mean \pm SEM ( $n=4)$. ns, not significant, ${ }^{* *} P<0.001$ 
Isolated mESC-CMs were infected with adenoviral vectors for knockdown or overexpression of TRPC7 (Supplementary Fig. 2). Our data showed that, in spontaneously beating $\mathrm{mESC}-\mathrm{CMs}$, compared with controls, knockdown of TRPC7 decreased $(1.71 \pm 0.20$ vs $1.09 \pm$ $0.18 \mathrm{~Hz}, \quad n=17-19, \quad P<0.05$ ) (Fig. 2a-c), while overexpression of TRPC7 increased $(1.90 \pm 0.17$ vs $3.10 \pm 0.29 \mathrm{~Hz}, n=17, P<0.01)$ the frequency of CaTs (Fig. 2j-l).

The change of TRPC7 expression also led to an alteration of CaT kinetics. Specifically, when compared with controls, knockdown of TRPC7 increased the time-to-

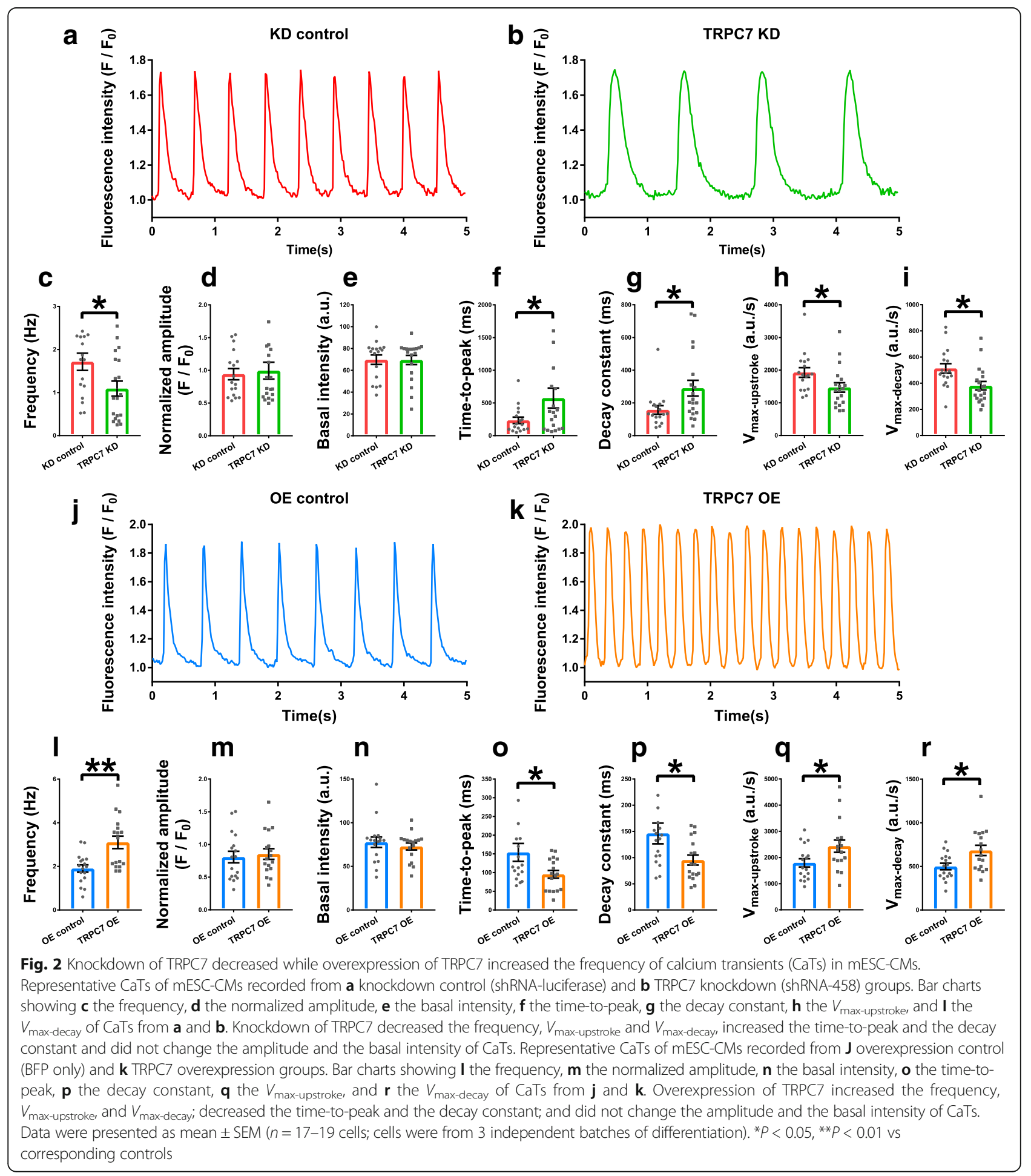


peak $(233.71 \pm 49.43$ vs $574.79 \pm 152.80 \mathrm{~ms}, n=17-19$, $P<0.05)$ and the decay constant $(157.24 \pm 26.10$ vs $289.95 \pm 48.09 \mathrm{~ms}, n=17-19, P<0.05)$ of CaTs, and decreased the maximum upstroke velocity $(1928.48 \pm$ 147.95 vs $1470.30 \pm 143.69$ a.u./s, $n=17-19, \quad P<0.05)$ and the maximum decay velocity $(512.74 \pm 36.51$ vs $380.60 \pm 32.41$ a.u./s, $n=17-19, \quad P<0.05$ ) (Fig. 2 f-i), while overexpression of TRPC7 decreased the time-topeak $(153.82 \pm 23.88$ vs $95.29 \pm 10.32 \mathrm{~ms}, n=17, P<0.05)$ and the decay constant $(146.12 \pm 19.82$ vs $95.41 \pm 9.61 \mathrm{~ms}$, $n=17, P<0.05)$ and increased the maximum upstroke velocity $(1794.65 \pm 158.36$ vs $2432.61 \pm 235.16$ a.u./s, $n=$ $17, P<0.05)$ and the maximum decay velocity $(499.02 \pm$ 37.04 vs $682.73 \pm 59.05$ a.u./s, $n=17, P<0.05$ ) (Fig. $2 o-$ r). On the other hand, neither knockdown nor overexpression of TRPC7 altered the amplitude and the basal level of CaTs (Fig. 2d, e, m, n). The data suggested that TRPC7 positively regulated the frequency and kinetics of $\mathrm{CaTs}$.

Given the importance of LCRs in ticking $\mathrm{Ca}^{2+}$ clock and coupling SR Ca ${ }^{2+}$ release to the inward $I_{\mathrm{NCX}}$ to accelerate the late DD [7], whether TRPC7 would regulate LCRs was further tested. We found that, compared with controls, knockdown of TRPC7 decreased $(28.52 \pm 4.26$ vs $15.39 \pm 2.69$ sparks $/ 100 \mu \mathrm{m} / \mathrm{s}, \quad n=10-11, P<0.05$ ) (Fig. 3a-c), while overexpression of TRPC7 increased $(30.97 \pm 4.50$ vs $49.84 \pm 6.58$ sparks $/ 100 \mu \mathrm{m} / \mathrm{s}, n=10-11$, $P<0.05$ ) (Fig. $3 \mathrm{~g}-\mathrm{i}$ ) the frequency of LCRs. Neither knockdown nor overexpression of TRPC7 altered the amplitude, full width at half-maximum (FWHM), and full duration at half-maximum (FDHM) of LCRs (Fig. 3d-f, j-l). Our data suggested that TRPC7 positively regulated the frequency of LCRs without affecting the amplitude and kinetics of LCRs.

\section{TRPC7 positively regulated spontaneous APs in mESC-} $\mathrm{CMs}$ by affecting the diastolic depolarization rate (DDR) Besides $\mathrm{Ca}^{2+}$ clock, membrane clock is another determinant of automaticity, we then moved on to examine if TRPC7 would regulate spontaneous APs. Whole-cell current-clamp technique was used to measure APs in spontaneously beating mESC-CMs. Consistent with the data of $\mathrm{Ca}^{2+}$ imaging, when compared with controls, knockdown of TRPC7 slowed down $(1.68 \pm 0.24$ vs $0.97 \pm 0.14 \mathrm{~Hz}, n=12-14, P<0.05$ ) (Fig. $4 \mathrm{a}-\mathrm{c}$ ), while overexpression of TRPC7 accelerated $(1.66 \pm 0.26$ vs $3.16 \pm 0.40 \mathrm{~Hz}, n=11-12, P<0.01$ ) (Fig. $4 \mathrm{~h}-\mathrm{j}$ ) the AP firing rate in $\mathrm{mESC}-\mathrm{CMs}$. To further investigate how TRPC7 modulated the AP morphology and changed the rate of AP, several important parameters of AP were analyzed. The data showed that, compared with controls, knockdown of TRPC7 reduced $(49.53 \pm 8.43$ vs $20.75 \pm$ $3.61 \mathrm{mV} / \mathrm{s}, n=12-14, P<0.01$ ) (Fig. $4 \mathrm{~d}$ ), while overexpression of TRPC7 increased $(37.89 \pm 8.35$ vs $116.71 \pm 22.42$ $\mathrm{mV} / \mathrm{s}, n=11-12, P<0.01$ ) (Fig. $4 \mathrm{k}$ ) the DDR without affecting other parameters including the amplitude, the $\mathrm{APD}_{50}$, and the maximum diastolic potential (MDP) of APs (Fig. 4e-g, l-n).

\section{TRPC7 positively regulated the activity of RyR2 and SERCA but not IP3R in mESC-CMs}

Based on the observation that TRPC7 positively regulated the frequency and kinetics of CaTs, we sought to explore the underlying mechanism. To fulfill this purpose, TRPC7 was knocked down in mESCCMs and the activity of RyR2, SERCA, and IP3R was subsequently evaluated as these proteins play critical roles in $\mathrm{Ca}^{2+}$ handling. A pharmacological method was adopted for the evaluation. Specifically, $10 \mu \mathrm{M}$ ryanodine, $0.5 \mu \mathrm{M}$ thapsigargin ( $\mathrm{Tg}$ ), and $20 \mu \mathrm{M} \mathrm{2-}$ aminoethoxydipheylborate (2-APB) were applied to $\mathrm{mESC}-\mathrm{CMs}$ to inhibit the activity of RyR2, SERCA, and IP3R, respectively; the response of cells was measured by $\mathrm{Ca}^{2+}$ imaging using confocal microscopy. We found that ryanodine decreased the frequency and the maximum upstroke velocity of CaTs in both control and TRPC7 knockdown mESC-CMs. But the extent of decrease was smaller in TRPC7-knockdown cells than control cells in terms of the frequency $(50.15 \% \pm$ $15.86 \%$ vs $70.49 \% \pm 22.29 \%, n=10, P<0.05)$ and the maximum upstroke velocity $(28.03 \% \pm 2.54 \%$ vs $42.66 \% \pm 3.86 \%, n=10, P<0.01$ ) (Fig. 5a-f). Likewise, thapsigargin decreased the frequency and the maximum decay velocity of CaTs, with a smaller extent observed in TRPC7-knockdown cells than control cells in terms of both the frequency $(51.44 \% \pm 16.27 \%$ vs $75.14 \% \pm 23.76 \%, n=10, P<0.05)$ and the maximum decay velocity $(47.74 \% \pm 5.24 \%$ vs $66.63 \% \pm 5.39 \%, n=10$, $P<0.05$ ) and (Fig. 5g-1). Although 2-APB decreased the maximum upstroke velocity and amplitude, the extent was similar between TRPC7-knockdown cells and control cells (Fig. 5m-r). We reasoned that knockdown of TRPC7 had already diminished the activity of both RyR2 and SERCA (but not IP3R), so smaller inhibitory efficacy was observed when blockers of RyR2 and SERCA (but not that of IP3R) were applied.

\section{TRPC7 positively regulated $I_{\mathrm{NCX}}$ but not $I_{\mathrm{f}}$ in $\mathrm{mESC}-\mathrm{CMs}$}

$I_{\mathrm{f}}$ has been regarded as the pacemaking current because it is the main contributor to the early DD. To study how TRPC7 positively regulates the frequency and DDR of APs, we knocked down TRPC7 in mESC-CMs and tried to detect the change of $I_{\mathrm{f}}$. We found that TRPC7 knockdown did not affect the $I_{\mathrm{f}}$ in mESC-CMs (Fig. 6a-c). To confirm the specificity of $I_{\mathrm{f}}, 5 \mathrm{mM} \mathrm{CsCl}$ was applied to the bath solution of mESC-CMs infected with knockdown control adenovirus. It was found that $\mathrm{CsCl}$ dramatically decreased the current, confirming that the current record from this protocol was $I_{\mathrm{f}}$. 


\section{a}

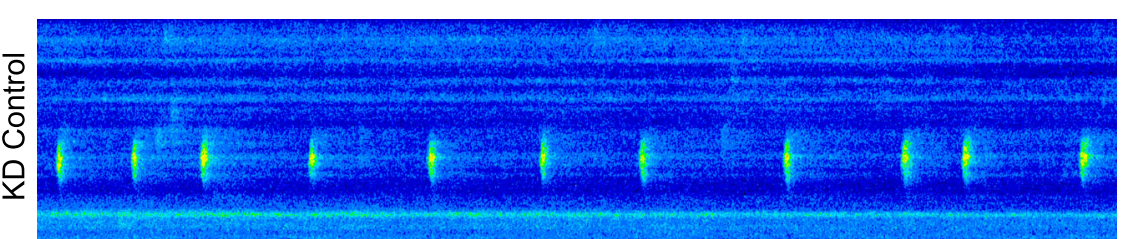

b
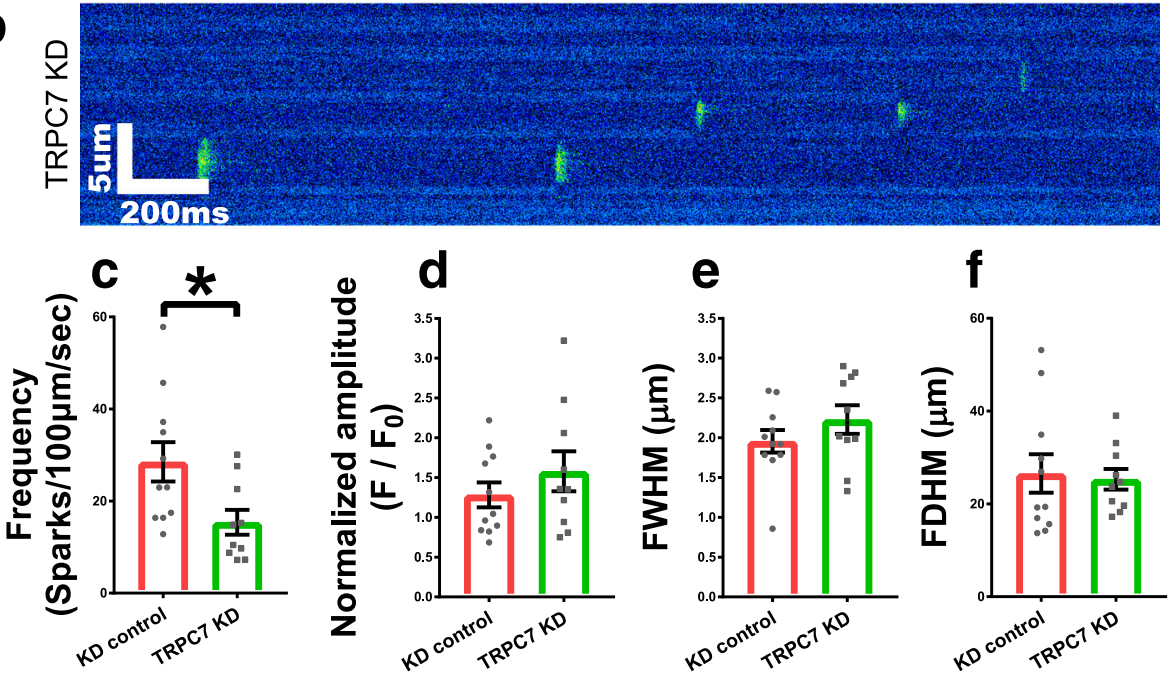

g

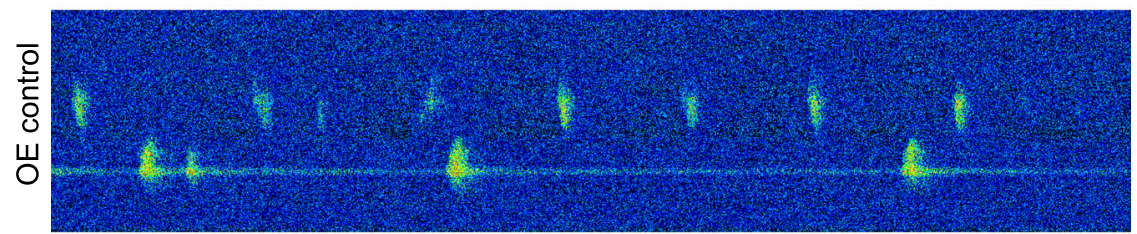

h
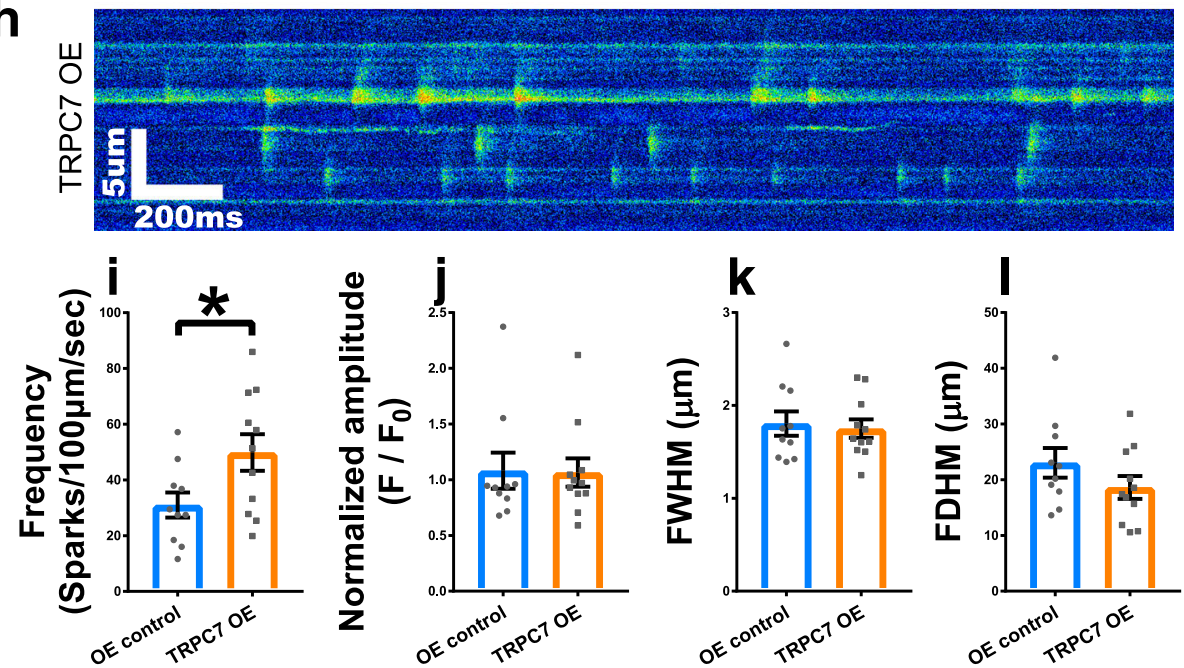

Fig. 3 Knockdown of TRPC7 decreased while overexpression increased the frequency of localized calcium releases (LCRs) in mESC-CMs. Representative LCRs of mESC-CMs recorded from a knockdown control (shRNA-luciferase) and b TRPC7 knockdown (shRNA-458) groups. Bar charts showing $\mathbf{c}$ the frequency, $\mathbf{d}$ the amplitude, e the full width at half-maximum (FWHM), and $\mathbf{f}$ the full duration at half-maximum (FDHM) of LCRs from $\mathbf{a}$ and $\mathbf{b}$. Knockdown of TRPC7 decreased the frequency of LCRs without affecting other parameters. Representative LCRs of mESC-CMs recorded from $\mathbf{g}$ overexpression control (BFP only) and $\mathbf{h}$ TRPC7 overexpression groups. Bar charts showing $\mathbf{i}$ the frequency, $\mathbf{j}$ the amplitude, $\mathbf{k}$ the FWHM, and $\mathbf{I}$ the FDHM of LCRs from $\mathbf{g}$ and $\mathbf{h}$. Overexpression of TRPC7 increased the frequency of LCRs without affecting other parameters. Data were presented as mean \pm SEM ( $n=10-11$ cells; cells were from 5 independent batches of differentiation). ${ }^{*} P<0.05$ vs corresponding controls 


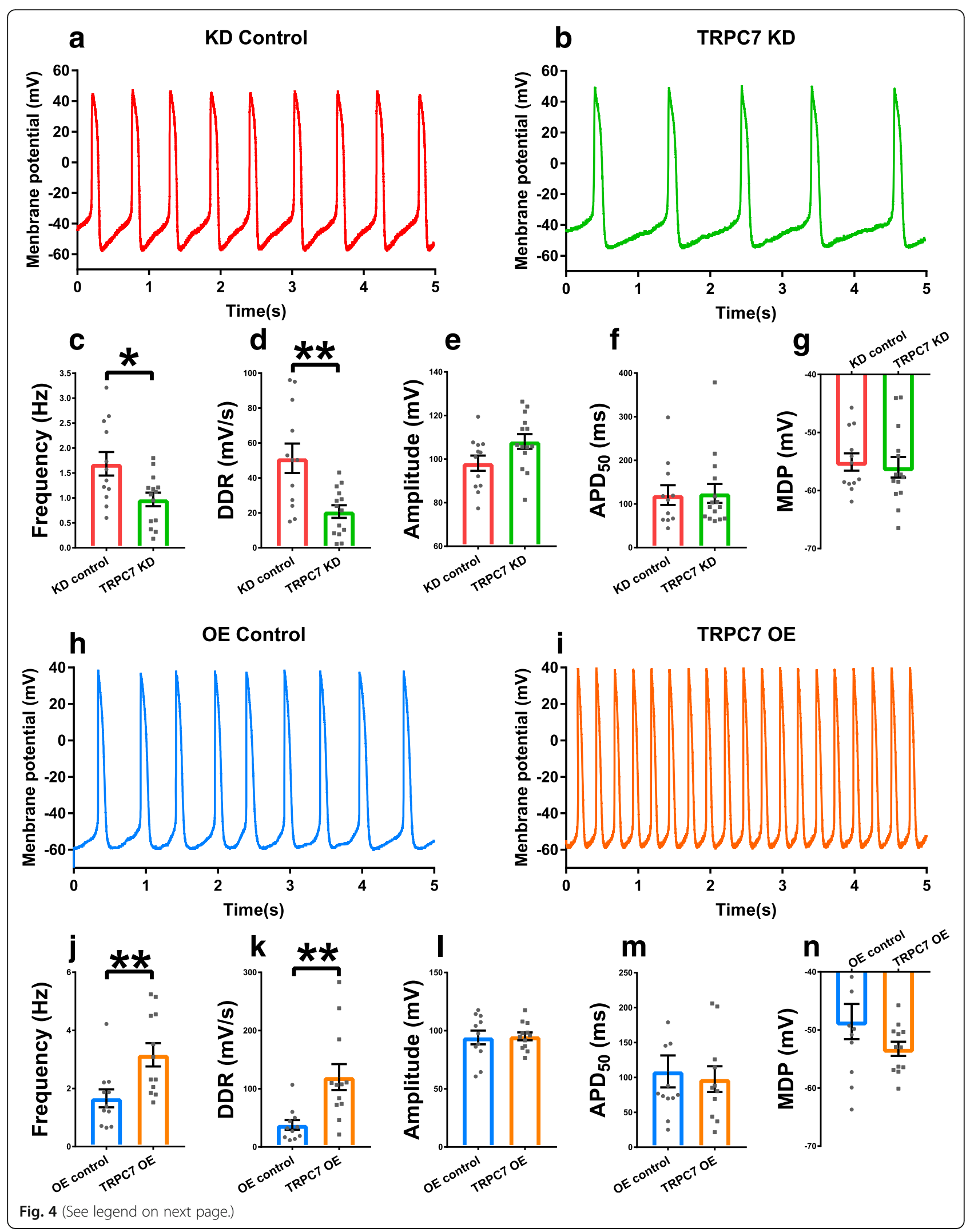


(See figure on previous page.)

Fig. 4 Knockdown of TRPC7 decreased while overexpression of TRPC7 increased the frequency of action potentials (APs) in mESC-CMs. Representative APs of mESC-CMs recorded from a knockdown control (shRNA-luciferase) and $\mathbf{b}$ TRPC7 knockdown (shRNA-458) groups. Bar charts showing $\mathbf{c}$ the frequency, $\mathbf{d}$ the diastolic depolarization rate (DDR), e the amplitude, $\mathbf{f}$ the $50 \%$ action potential duration (APD 50 ), and $\mathbf{g}$ the maximum diastolic potential (MDP) of APs from $\mathbf{a}$ and $\mathbf{b}$. Knockdown of TRPC7 decreased the frequency and DDR without affecting the amplitude, $\mathrm{APD}_{50}$ and MDP of APs. Representative APs of mESC-CMs recorded from $\mathbf{h}$ overexpression control (BFP only) and $\mathbf{i}$ TRPC7 overexpression groups. Bar charts showing $\mathbf{j}$ the frequency, $\mathbf{k}$ the DDR, I the amplitude, $\mathbf{m} \mathrm{APD}_{50}$, and $\mathbf{n}$ the MDP of APs from $\mathbf{h}$ and $\mathbf{i}$. Overexpression of TRPC7 increased the frequency and DDR without affecting the amplitude, APD 50 and MDP of APs. Data were presented as mean $\pm \operatorname{SEM}\left(n=11-14\right.$ cells; cells were from 5 independent batches of differentiation). ${ }^{*} P<0.05,{ }^{* *} P<0.01$ vs corresponding controls

In contrast to $\mathrm{HCN}$ channels which contribute to the early DD, NCX is believed to accelerate the late DD. We found that knockdown of TRPC7 decreased the $I_{\mathrm{NCX}}$ at both $-100 \mathrm{mV}(-4.06 \pm 0.55$ vs $-2.15 \pm 0.24 \mathrm{pA} / \mathrm{pF}$, $n=15, P<0.01)$ and $+50 \mathrm{mV}(4.70 \pm 0.56$ vs $3.16 \pm 0.28$ pA/ pF, $n=15, P<0.05$ ) (Fig. 7a, c, d). On the other hand, overexpression of TRPC7 increased $I_{\mathrm{NCX}}$ at both $-100 \mathrm{mV}(-4.12 \pm 0.71$ vs $-7.68 \pm 1.14 \mathrm{pA} / \mathrm{pF}, n=14$, $P<0.05)$ and $+50 \mathrm{mV}(5.02 \pm 0.61$ vs $8.48 \pm 1.03 \mathrm{pA} / \mathrm{pF}$, $n=14, P<0.01$ ) (Fig. 7b, e, f). The data suggested TRPC7 could positively regulate the activity of NCX.
TRPC7 did not affect the expression of several important proteins relevant to the automaticity

TRPC7 is a $\mathrm{Ca}^{2+}$ permeable channel and $\mathrm{Ca}^{2+}$ entry is a very important mechanism by which gene expression pattern is modulated and cellular functions are shaped. Given the ability of TRPC7 to regulate the activity of the channel/pump/exchanger, we further examined whether TRPC7 could regulate the expression of several proteins relevant to the automaticity using NRVMs (which had a high percentage of purity; Supplementary Fig. 3). By Western blotting, the expression of HCN4, Cav1.3,
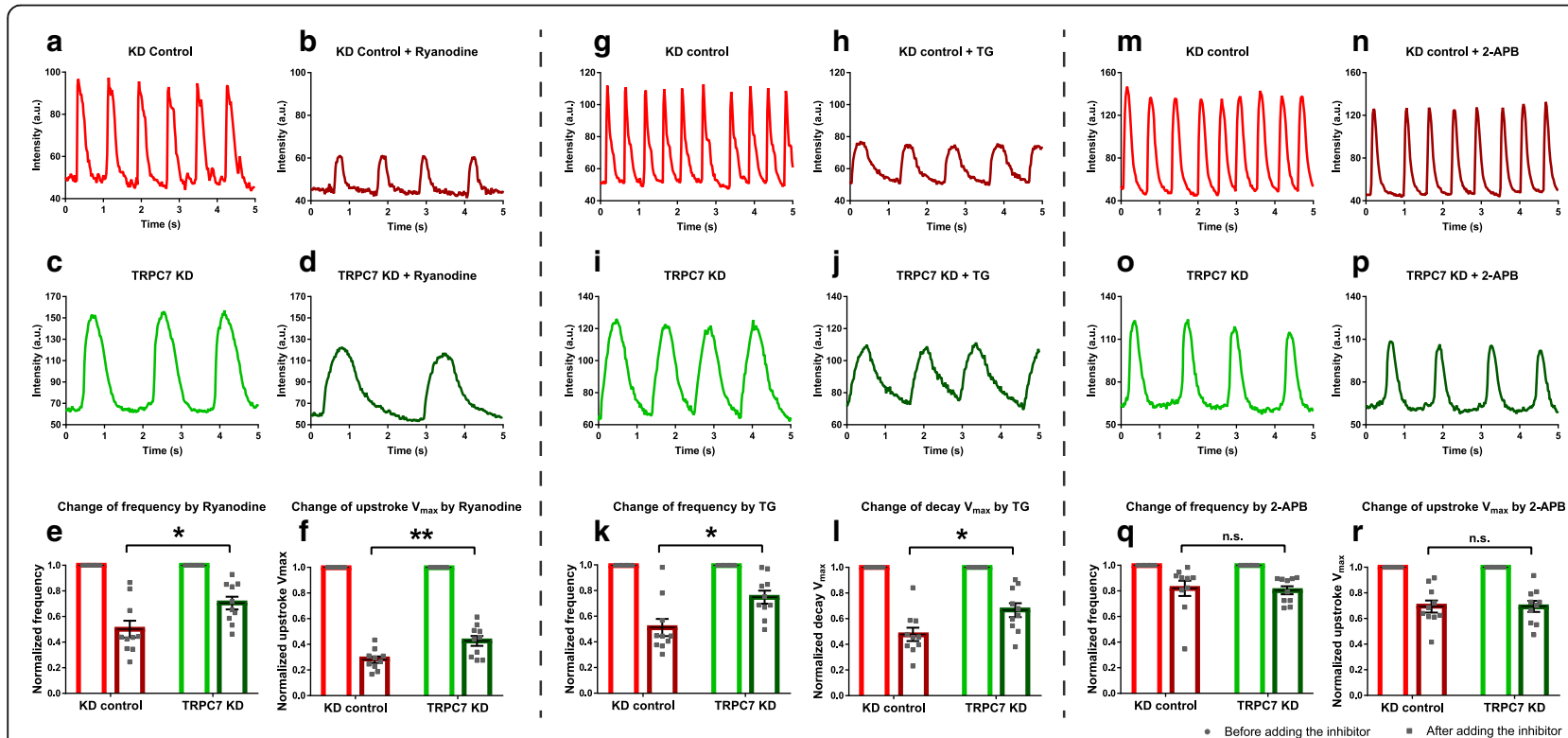

Fig. 5 Knockdown of TRPC7 decreased the activity of RyR2 and SERCA without affecting the activity of IP3R in mESC-CMs. Representative CaTs recorded from the control group $\mathbf{a}$ before and $\mathbf{b}$ after applying ryanodine. Representative CaTs recorded from TRPC7 knockdown group $\mathbf{c}$ before and $\mathbf{d}$ after applying ryanodine. e, $\mathbf{f}$ Bar charts showing the normalized frequency and the $V_{\text {max-upstroke }}$ calculated from a-d. The decrease of the frequency and the $V_{\text {max-upstroke }}$ caused by ryanodine was less in TRPC7 knockdown group. Representative CaTs recorded from the control group $\mathbf{g}$ before and $\mathbf{h}$ after applying thapsigargin (TG). Representative CaTs recorded from TRPC7 knockdown group i before and $\mathbf{j}$ after applying TG. $\mathbf{k}$, I Bar charts showing the normalized frequency and $V_{\text {max-decay }}$ calculated from $\mathbf{g}$-j. The decrease of the frequency and the $V_{\text {max-decay }}$ and amplitude caused by TG was less in TRPC7 knockdown group. Representative CaTs recorded from the control group $\mathbf{m}$ before and $\mathbf{n}$ after applying 2aminoethoxydipheylborate (2-APB). Representative CaTs recorded from TRPC7 knockdown group o before and $\mathbf{p}$ after applying 2-APB. q, $\mathbf{r}$ Bar charts showing the normalized frequency and the $V_{\text {max-upstroke }}$ calculated from $\mathbf{m}$ - $\mathbf{p}$. The decrease of the frequency and the $V_{\text {max-upstroke }}$ caused by 2-APB was similar between control and TRPC7 knockdown groups. Data were presented as mean \pm SEM ( $n=10$ cells; cells were from 3 independent batches of differentiation). ${ }^{*} P<0.05,{ }^{* *} P<0.01$ vs control 


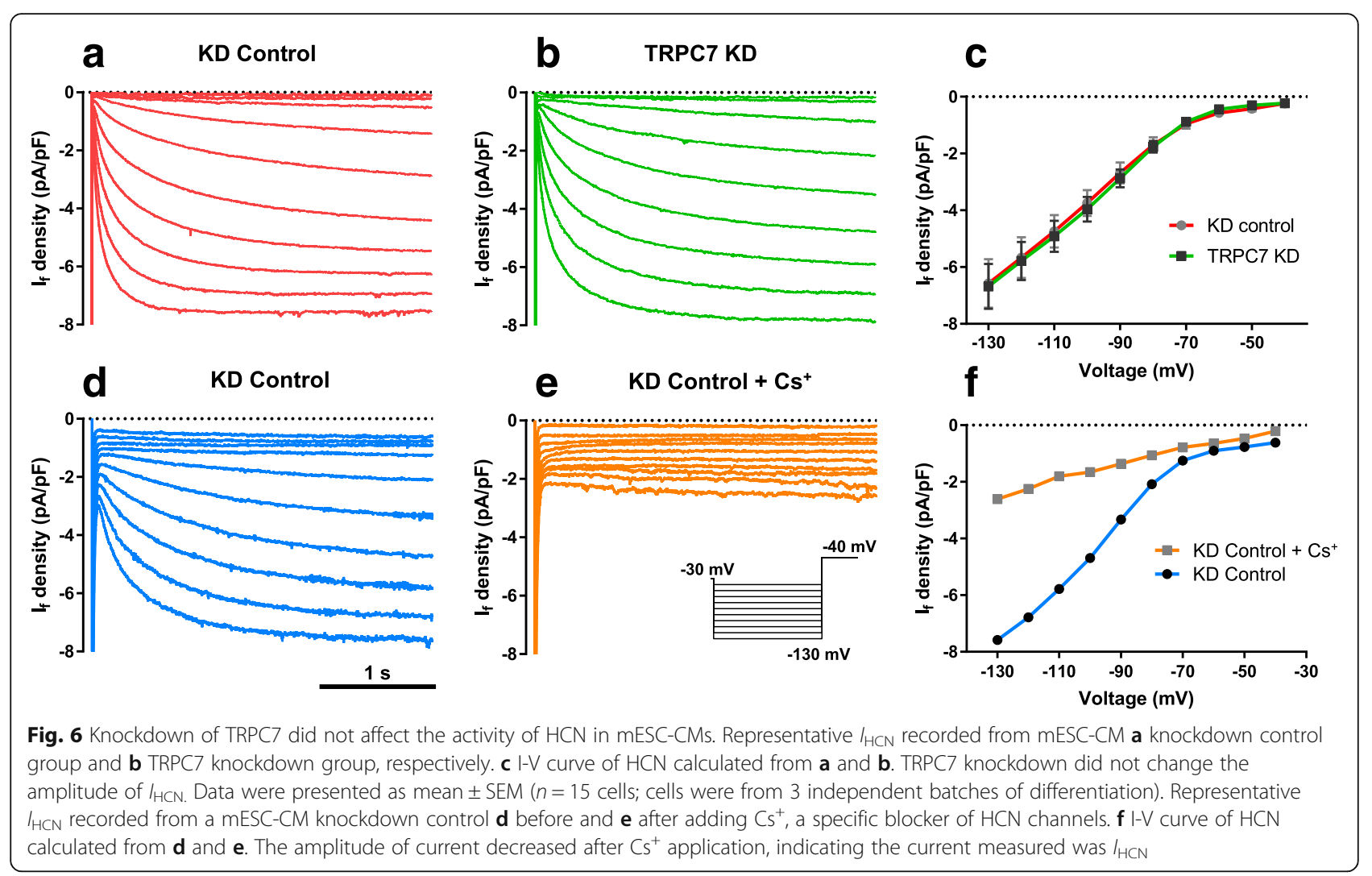

Cav3.1, Cav3.2, RyR2, SERCA, and IP3R1 was detected after TRPC7 knockdown or overexpression in NRVMs. We found that, when compared to controls, neither knockdown nor overexpression of TRPC7 changed the expression of all these proteins (Figs. 8 and 9a, e).

TRPC7 regulated the activity of RyR2 and SERCA through phosphorylation of RyR2 and PLN respectively

It has been well documented that phosphorylation of RyR2 and PLN regulated the activity of RyR2 [35] and SERCA [36], respectively. We had observed the positive regulation of TRPC7 to the activity of both RyR2 and SERCA. We then tested whether TRPC7 could affect the phosphorylation of RyR2 and PLN which in turn affect the activity of RyR2 and SERCA. TRPC7 was knocked down or overexpressed in NRVMs and phosphorylated RyR2 [p(S2814)RyR2] and phosphorylated PLN [p(T17)PLN] were detected by Western blotting. We found that while the total expression of RyR2 and PLN was not altered, both $\mathrm{p}(\mathrm{S} 2814)$ RyR2 and $\mathrm{p}(\mathrm{T} 17)$ PLN decreased after TRPC7 knockdown, and increased after TRPC7 overexpression (Fig. 9).

\section{Regulation of spontaneous APs by TRPC7 was $\mathrm{Ca}^{2+}$ dependent}

Due to the absence of specific pharmacological activators and inhibitors of TRPC7, it was difficult to directly dissect the effect exerted by the $\mathrm{Ca}^{2+}$ entry mediated by TRPC7. To overcome this problem, we developed a dominant negative of TRPC7, which consists of the $\mathrm{N}$ terminus of TRPC7, to specifically diminish the $\mathrm{Ca}^{2+}$ permeability of TRPC7. The efficacy of TRPC7 dominant negative (TRPC7-N) was proven by the ectopic expression in HEK-293-FT cells and $\mathrm{Ca}^{2+}$ imaging. To measure the $\mathrm{Ca}^{2+}$ entry from the external environment, HEK-293-FT cells were initially bathed in $\mathrm{Ca}^{2+}$-free Tyrode's solution. One hundred micromoles carbachol was applied to activate muscarinic acetylcholine receptors and subsequently PLC. Activation of PLC generated two products, IP3 and DAG which elicit $\mathrm{Ca}^{2+}$ release from ER (mediated by IP3R) and $\mathrm{Ca}^{2+}$ entry from the external environment (mediated by channels on plasma membrane), respectively. When the cells were bathed in $\mathrm{Ca}^{2+}$ free solution, the increase of intracellular $\mathrm{Ca}^{2+}$ represent the $\mathrm{Ca}^{2+}$ release from ER only. When the cytosolic $\mathrm{Ca}^{2+}$ was restored to a stable level, $1.8 \mathrm{mM} \mathrm{Ca}^{2+}$ was then applied to the bath solution, those channels activated by DAG now permeated $\mathrm{Ca}^{2+}$ and caused the cytosolic $\mathrm{Ca}^{2+}$ increase. By this method, $\mathrm{Ca}^{2+}$ entry from the external can be distinguished from $\mathrm{Ca}^{2+}$ release from ER. TRPC7-N was found not to mediate $\mathrm{Ca}^{2+}$ entry and co-expression of TRPC7-N with wild-type TRPC7 significantly decreased the permeability of TRPC7 (Figs. 10a-b). By overexpressing this TRPC7-N in mESC-CMs, we found that, when 


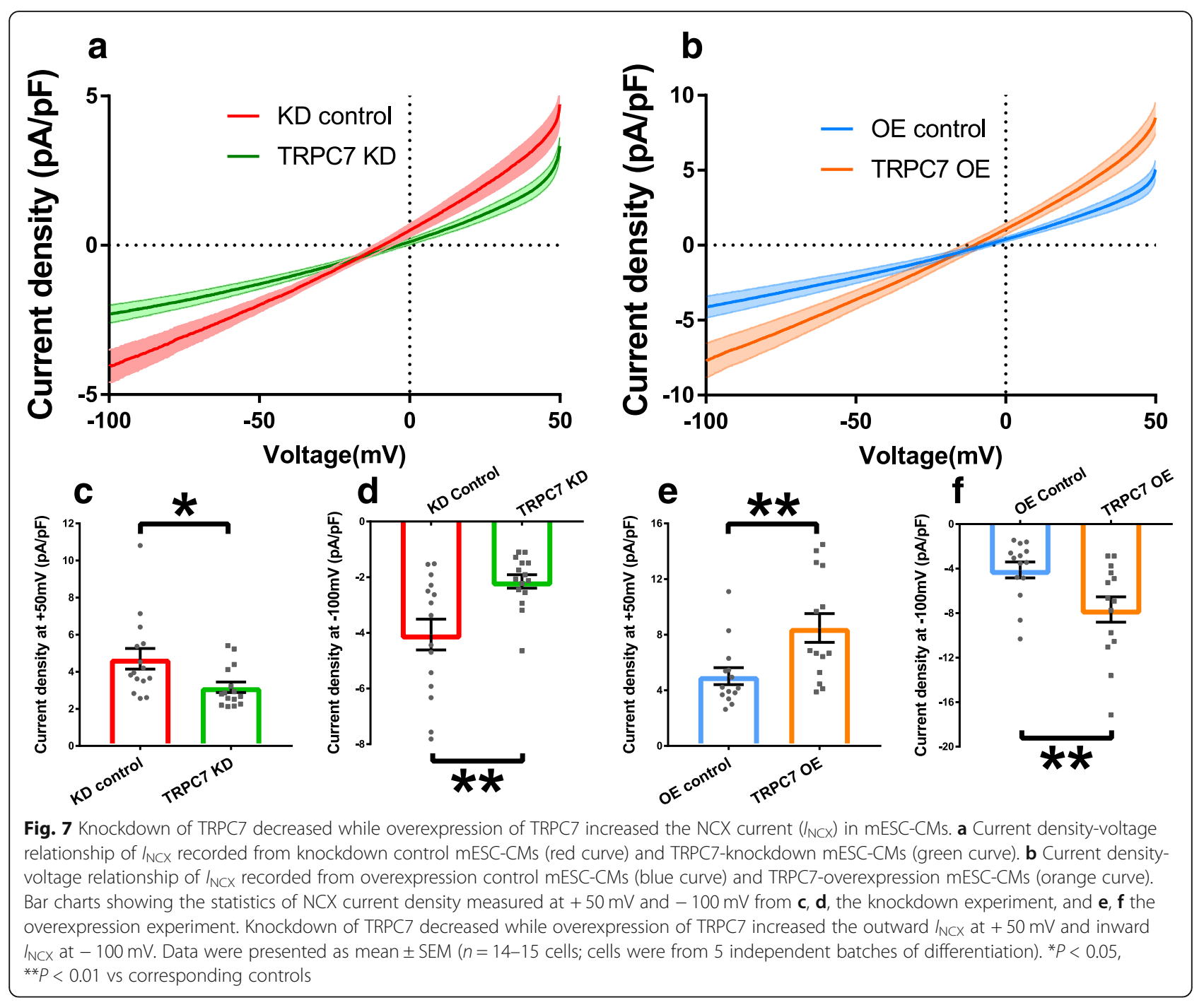

compared to the control group, APs $(1.88 \pm 0.14$ vs $1.16 \pm$ $0.13 \mathrm{~Hz}, n=17-18, P<0.01)$ and DDR $(46.48 \pm 6.51$ vs $28.23 \pm 5.49, n=17-18, P<0.05)$ were both decreased (Fig. 10c-i), similar to the effect of TRPC7 knockdown (cf. Fig. $4 \mathrm{a}-\mathrm{g}$ ). These results suggested that positive regulation of TRPC7 to the APs is $\mathrm{Ca}^{2+}$-dependent.

\section{Discussion}

In this work, mESC-CMs were used as a model to study the function of TRPC7 in regulating the automaticity. The major findings are the following: (1) The expression of TRPC7 is increased during the differentiation of mESCCMs. (2) TRPC7 can positively regulate the automaticity of $\mathrm{mESC}-\mathrm{CMs}$ as shown by the positive regulation of $\mathrm{CaTs}$, LCRs, and APs. (3) The regulation of CaTs by TRPC7 is implemented by regulating the activity of both RyR2 and SERCA but not their expression. (4) TRPC7 regulates the APs through the modulation of the NCX's activity. (5) The effect of TRPC7 to the automaticity is $\mathrm{Ca}^{2+}$-dependent.
TRPC7 positively regulates the $\mathrm{Ca}^{2+}$ clock of automaticity Spontaneous, rhythmic $\mathrm{Ca}^{2+}$-driven events occurred on cardiac SR are referred to as the $\mathrm{Ca}^{2+}$ clock, a very important mechanism for pacemaker cells to realize the automaticity [8]. The functioning of $\mathrm{Ca}^{2+}$ clock requires LCRs (also called $\mathrm{Ca}^{2+}$ sparks) and CaTs. LCRs are spontaneous, and elementary $\mathrm{Ca}^{2+}$ release mediated by transient openings of clusters of RyR2 on SR [37]. LCRs usually occur at the late stage of DD before the upstroke of an AP. Studies have shown that even without the stimulation of APs, LCRs can still take place with a frequency similar to that of APs [38]. So LCRs are thought to be a time-keeper of the $\mathrm{Ca}^{2+}$ clock. CaTs are the results of the $\mathrm{Ca}^{2+}$ influx through voltage-gated L-type $\mathrm{Ca}^{2+}$ channel (LTCCs) (on the plasma membrane), and the bulk $\mathrm{Ca}^{2+}$ release from SR triggered by the $\mathrm{Ca}^{2+}$-induced-Ca ${ }^{2+}$ release mechanism. CaTs are regarded as a synchrony of considerable $\mathrm{Ca}^{2+}$ sparks $[39,40]$; by this way, time of the $\mathrm{Ca}^{2+}$ clock is reset by APs every cycle. 


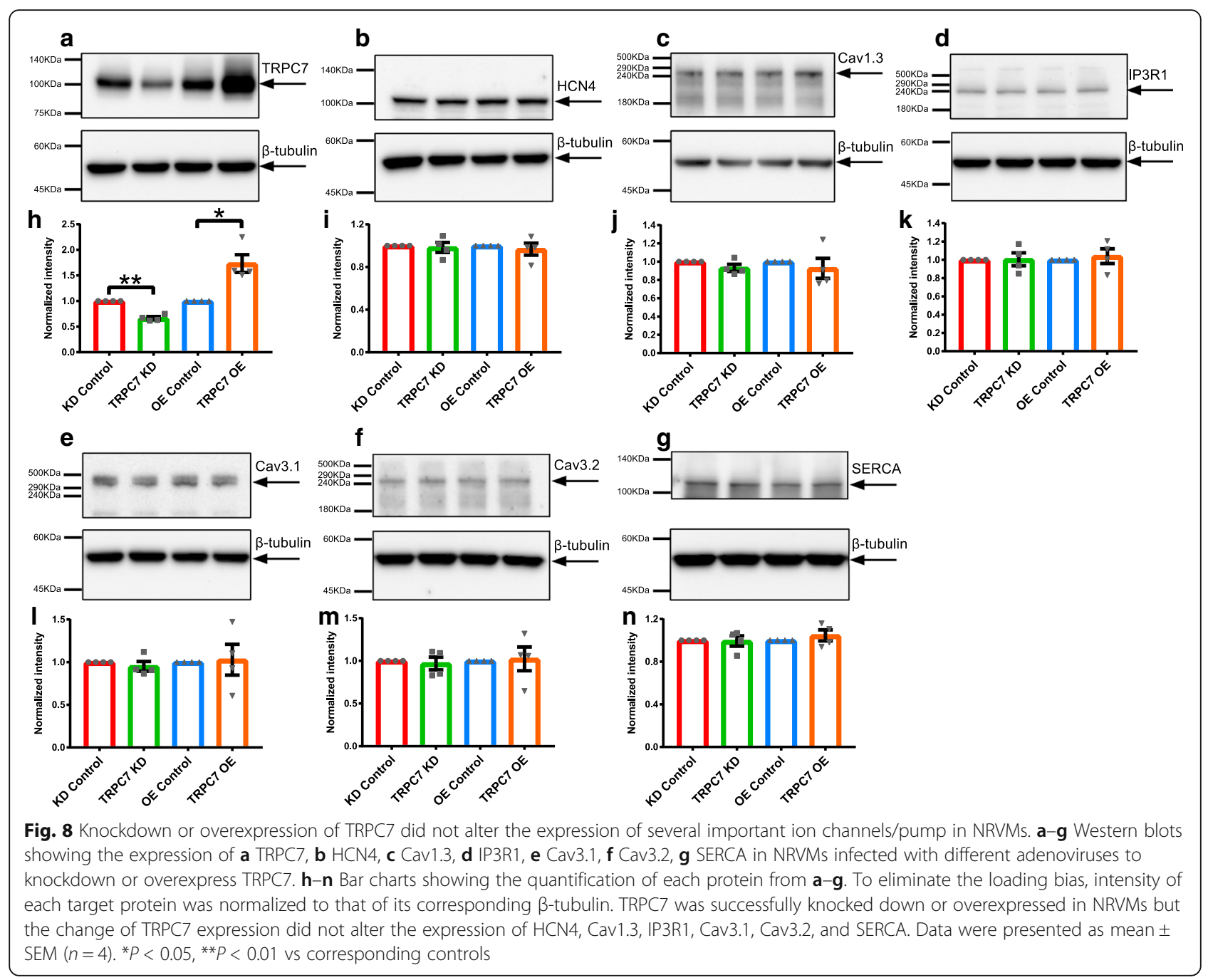

Our study showed that TRPC7 positively regulates both LCRs and CaTs and thus positively regulates the automaticity of mESC-CMs.

RyR2 and SERCA are two most important proteins on the SR to keep the $\mathrm{Ca}^{2+}$ clock running properly. RyR2 contributes to the $\mathrm{Ca}^{2+}$ release from SR, which is the basis to generate LCRs and CaTs. On contrary to RyR2, SERCA is responsible for reloading SR with $\mathrm{Ca}^{2+}$ to ensure the continual function of the $\mathrm{Ca}^{2+}$ clock. It has been documented that phosphorylation of RyR2 and PLN (an inhibitory protein partner of SERCA when it is in an unphosphorylated state) enhanced the activity of RyR2 [35] and SERCA [36], respectively, resulting in a positive regulation to the $\mathrm{Ca}^{2+}$ clock [41]. In line with previous reports, our data demonstrated that TRPC7 positively regulates the activity of RyR2 and SERCA via the phosphorylation of S2814 of RyR2 and T17 of PLN. We speculate that the phosphorylation may be mediated by CaMKII because S2814 of RyR2 and T17 of PLN are both catalytical sites of CaMKII $[35,36]$. Since the activity of CaMKII is $\mathrm{Ca}^{2+}$-dependent, it is possible that TRPC7, via mediating $\mathrm{Ca}^{2+}$ entry, modulates the activity of CaMKII which positively regulates the phosphorylation of RyR2 and PLN and thereby the activity of RyR2 and SERCA (Fig. 11).

\section{TRPC7 positively regulates the membrane clock of automaticity}

Various ion channels and exchangers located on the plasma membrane, which contribute to the spontaneous APs, work together to function as the membrane clock. Membrane clock is the other mechanism determining the automaticity. Our study showed that TRPC7 could positively regulate the spontaneous APs and therefore positively regulate the automaticity of $\mathrm{mESC}-\mathrm{CMs}$.

For those cardiac cells with automaticity (pacemaker cells), DD in phase 4 of APs is the most special feature to distinguish them from other working cardiomyocytes. After reaching the MDP in pacemaker cells, background current decreases while $I_{\mathrm{f}}$ current increases gradually, resulting in the early DD. While we found that TRPC7 


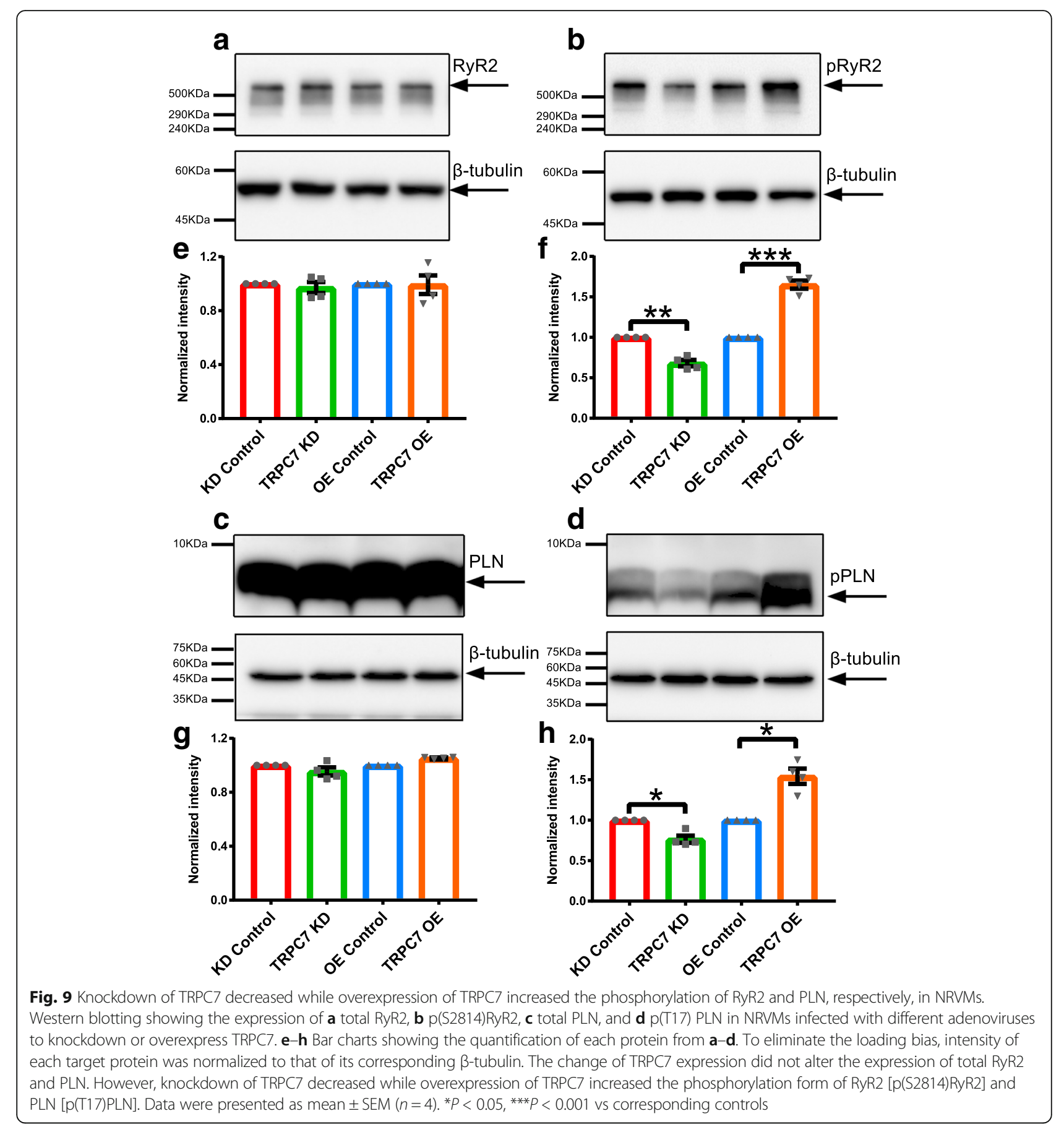

positively regulates the DDR, TRPC7 exerts no impact on $I_{\mathrm{f}}$. The whole process of DD is like a relay race, while the athletes are different ion channels and an exchanger. The HCN channel kicks start the race, leading to the early DD, but $I_{\mathrm{f}}$ fades out near mid DD when the T-type $\mathrm{Ca}^{2+}$ channel becomes the next player, and NCX is the last player who contributes to the late DD. Our data demonstrated that TRPC7 positively regulates $I_{\mathrm{NCX}}$ and thereby positively regulates DDR.
It has been documented that the driving force of the activity of NCX mainly comes from $\mathrm{Ca}^{2+}$ released from SR though LCRs during late DD [7]. Because of the special proximity between SR and plasma membrane, $\mathrm{Ca}^{2+}$ released from SR could be moved out of the cells by NCX, thus generating a net inward current to further accelerate late DD. We speculate that TRPC7 positively regulates LCRs which subsequently regulates $I_{\mathrm{NCX}}$. But we cannot exclude the 


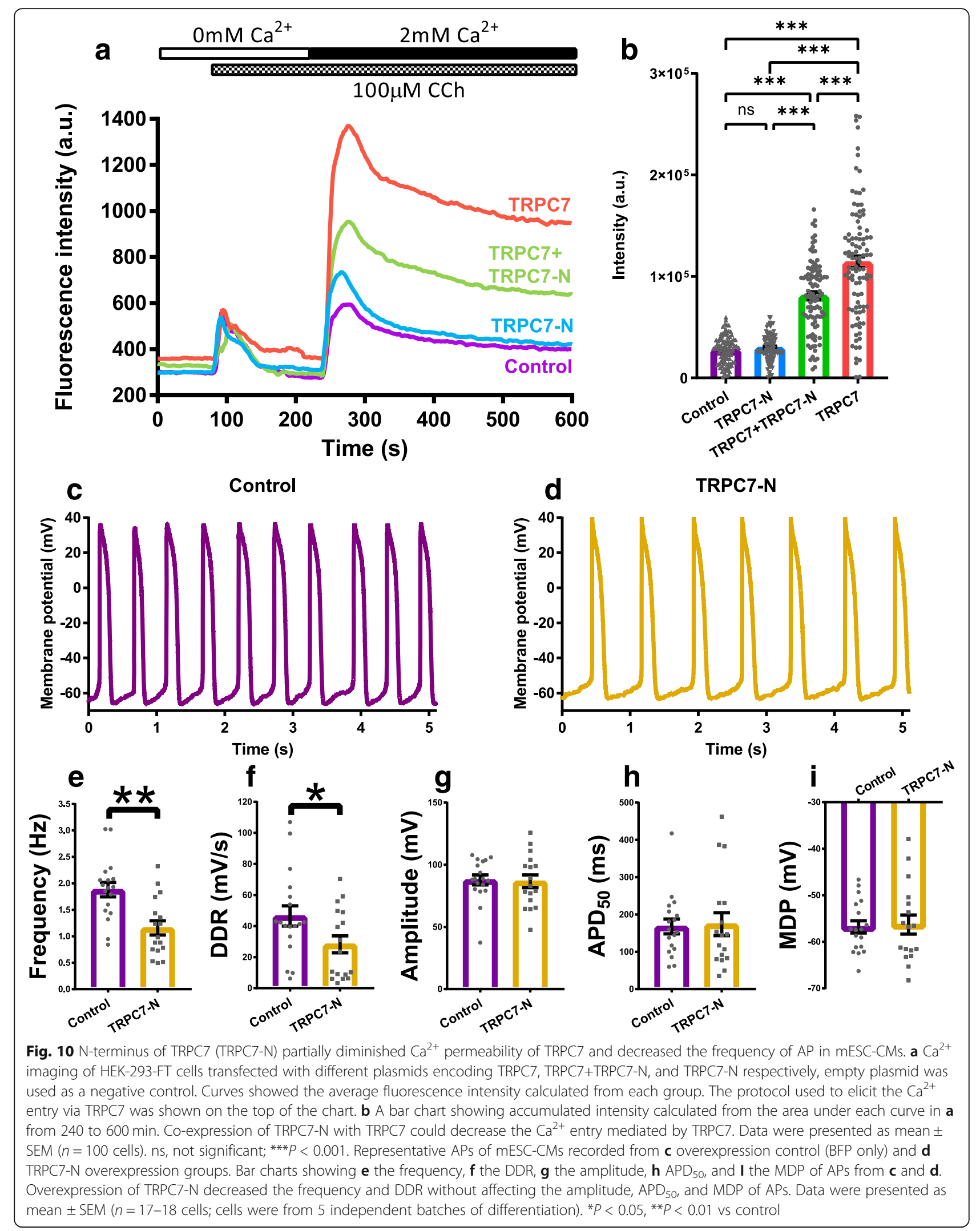




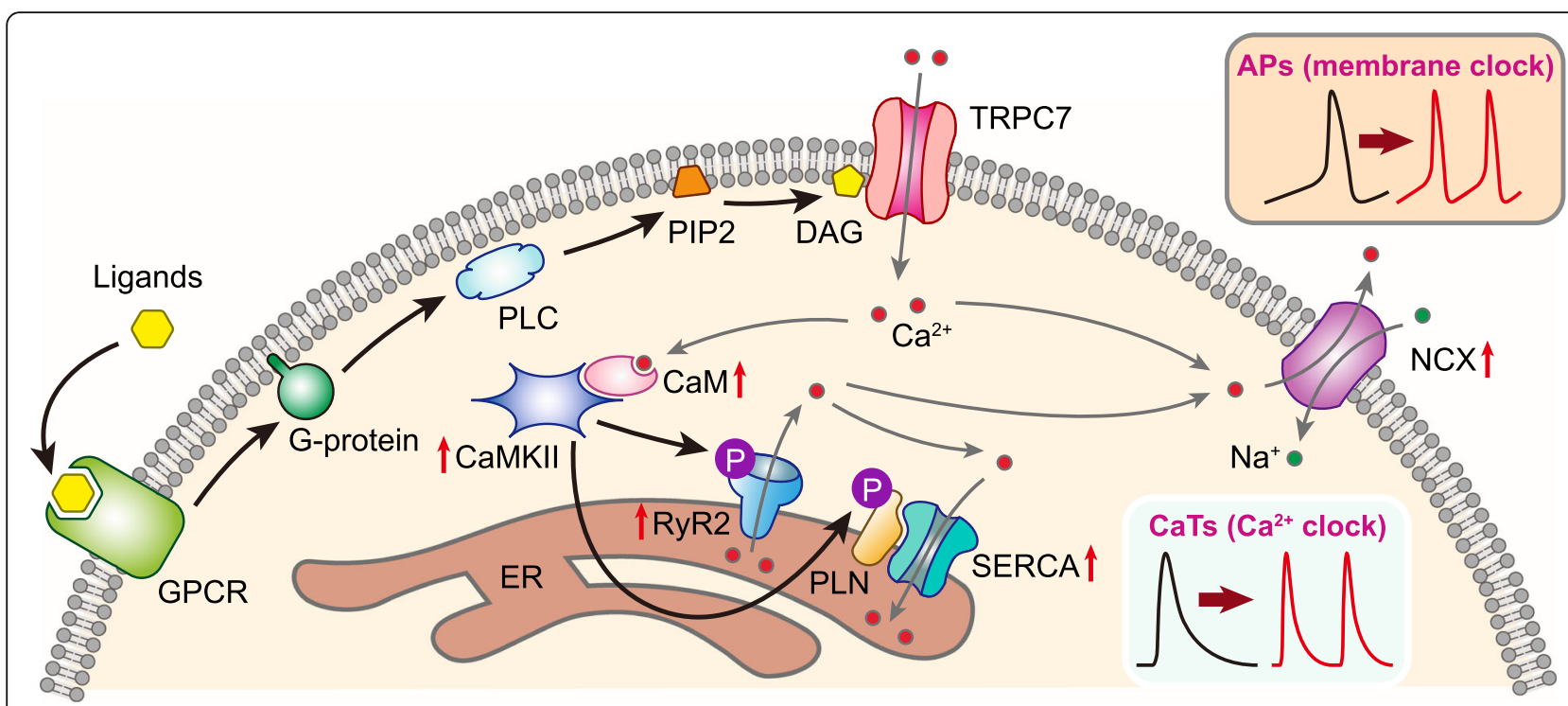

Fig. 11 Schematic diagram illustrating the mechanism through which TRPC7 positively regulates the automaticity of cardiomyocytes. G proteincoupled receptors (GPCRs) locating on the plasma membrane (PM) sense the external ligands such as hormones, neurotransmitters, and growth factors, transduce the signal to activate phospholipase C (PLC) which hydrolyzes the phosphatidylinositol 4,5-bisphosphate (PIP $)_{2}$ into inositol trisphosphate $\left(\mathrm{IP}_{3}\right)$ and diacylglycerol (DAG). TRPC7 is then directly activated by DAG, mediating the $\mathrm{Ca}^{2+}$ influx. Ca ${ }^{2+}$ permeated through TRPC7 may activate the forward mode of the $\mathrm{Na}^{+}-\mathrm{Ca}^{2+}$ exchanger (NCX), leading $\mathrm{Na}^{+}$influx and depolarization. This depolarization would then accelerate diastolic depolarization (DD) and increase AP firing rate. On the other hand, $\mathrm{Ca}^{2+}$ permeated through TRPC7 may also increase the activity of ryanodine receptor 2 (RyR2) locating on the SR, probably through CaMKII and phosphorylation of RyR2, leading to an increase of the localized calcium releases (LCRs). These LCRs are then coupled to inward NCX current, and subsequently accelerate the DD and AP firing rate. At the same time, CaMKII may also increase the phosphorylation of PLN, which subsequently increases the activity of SERCA. The enhancement of the activity of both RyR2 and SERCA result in the acceleration of CaTs

possibility that $\mathrm{Ca}^{2+}$ entry from TRPC7 could also directly activate NCX (Fig. 11).

\section{Conclusion}

In conclusion, our study has demonstrated that TRPC7 is a positive regulator of the automaticity in $\mathrm{mESC}-\mathrm{CMs}$. On the one hand, TRPC7 positively regulates the intracellular $\mathrm{Ca}^{2+}$ clock through the regulation of activities of both RyR2 and SERCA; on the other hand, TRPC7 also positively regulates the membrane clock via its influence on NCX activity. This makes TRPC7 a potential drug target to manipulate the AP firing rate of PSC-CM-based biological pacemakers to prevent tachyarrhythmia, a condition that might be encountered after PSC-CM transplantation.

\section{Abbreviations}

2-APB: 2-Aminoethoxydipheylborate; APs: Action potentials; CaTs: $\mathrm{Ca}^{2+}$ transients; CMs: Cardiomyocytes; cTnT: Cardiac troponin T; DAG: Diacylglycerol; DD: Diastolic depolarization; EB: Embryoid body; ESCCMs: Embryonic stem cell-derived cardiomyocytes; GPCRs: G protein-coupled receptors; HCN: Hyperpolarization-activated, cyclic nucleotide-gated channel; If: Funny current; IP3: 1,4,5-Trisphosphate; IP3R: Inositol trisphosphate receptor; LCRs: Local Ca ${ }^{2+}$ releases; LTCCs: L-type $\mathrm{Ca}^{2+}$ channels; NCX: Sodium-calcium exchanger; NRVMs: Neonatal rat ventricular myocytes; PIP2: Phosphatidylinositol 4,5-bisphosphate; PLC: Phospholipase C; PLN: Phospholamban; PSCs: Pluripotent stem cells; ROCC: Receptor-operated $\mathrm{Ca}^{2+}$ channel; RyR2: Ryanodine receptor 2; SERCA: Sarco/endoplasmic reticulum $\mathrm{Ca}^{2+}$-ATPase; SR: Sarcoplasmic reticulum; TG: Thapsigargin; TRPC7: Canonical transient receptor potential isoform 7

\section{Supplementary Information}

The online version contains supplementary material available at https://doi. org/10.1186/s13287-021-02308-7.

Additional file 1: Supplementary Figure 1. TRPC7 was expressed in cardiomyocytes. A - B, Representative images showing immunostaining of nuclei (blue), TRPC7 (green) and (A) CTnT (red), (B) a-actinin (red) in mESC-CMs. C - D, Representative images showing immunostaining of nuclei (blue), TRPC7 (green) and (C) CTnT (red), (D) a-actinin (red) in NRVMs. The positive staining of CTnT and aactinin suggested that these cells were cardiomyocytes, and the positive staining of TRPC7 indicated that the channel was expressed in cardiomyocytes. E, Representative images showing immunostaining of nuclei (blue), TRPC7 (green) and a-actinin (red) in NRVMs. In this experiment, the anti-TRPC7 was preincubated with its antigenic peptide to block its binding to TRPC7. The disappearance of TRPC7 staining signal suggested the specificity of the anti-TRPC7. Scale bars $=20 \mu \mathrm{m}$. Supplementary Figure2. TRPC7 was successfully knocked down and overexpressed in mESC-CMs. A - B, Overview of mESC-CMs infected by (A) TRPC7-knockdown adenovirus encoding GFP (Ad-CMV-GFP-U6shTRPC7) and (B) TRPC7-overexpression adenovirus encoding BFP (Ad-CMV-TRPC7-CMV-BFP). Abundant GFP- and BFP-positive cells suggested that the infection efficiency of the adenoviruses was very high. $C-D$, Representative images showing immunostaining of aactinin (yellow) and TRPC7 (red) in mESC-CMs infected by (C) knockdown-control and (D) TRPC7-knockdown adenoviruses. The positive signal of GFP (green) suggested that the cells were infected by adenoviruses. The intensity of TRPC7 signal decreased after infection with TRPC7-knockdown adenoviruses, suggesting the successful knockdown of TRPC7. E - F, Representative images showing immunostaining of HA (red) in mESC-CMs infected by (C) overexpressioncontrol and (D) Tag-TRPC7-overexpression adenoviruses. The positive signal of BFP (blue) suggested that the cells were infected by 
adenoviruses. The intensity of HA signal increased after infection with Tag-TRPC7-overexpression adenoviruses, suggesting the successful overexpression of TRPC7. Supplementary Figure 3. The purity of cardiomyocyte was high in the NRVM preparation. A - B, Representative images showing immunostaining of nuclei (blue) and (A) CTnT (red), (B) a-actinin (red) in NRVM preparation. In the images, only two cells with an identity other than cardiomyocyte was found (indicated by arrows), while all others were cardiomyocytes (15 out of 17 were cardiomyocytes). The purity of cardiomyocyte estimated from these images was more than $85 \%$. Scale bars $=20 \mu \mathrm{m}$.

\section{Acknowledgements}

We would like to thank Mr. YH Liang for his excellent technical support

\section{Authors' contributions}

$X L, R Z$, and $Q D$ performed the experiments. $X L$ performed the data analysis. $X L$ wrote the manuscript in consultation with SYT. SYT and XY were involved in planning and supervising the work. The authors read and approved the final manuscript.

\section{Funding}

This work was supported by the General Research Fund (14176817) from the University Grants Committee (UGC) of the Hong Kong SAR, and the Innovative Technology Fund of Innovation Technology Commission: Funding Support to Partner State Key Laboratories in Hong Kong. X.L., R.Z. and Q.D. were supported by the postgraduate studentships from the CUHK.

\section{Availability of data and materials}

The datasets used and/or analyzed during the current study are available from the corresponding author on reasonable request.

\section{Declarations}

\section{Ethics approval and consent to participate}

This study was approved by the Animal Experimentation Ethics Committee, the Chinese University of Hong Kong (17-006-MIS), and conformed to Guide for the Care and Use of Laboratory Animals published by the US National Institutes of Health (NIH Publication No. 80-23, revised 2011).

\section{Consent for publication}

Not applicable.

\section{Competing interests}

The authors declare that they have no competing interests.

\section{Author details}

${ }^{1}$ School of Life Sciences, The Chinese University of Hong Kong, Hong Kong SAR, China. ${ }^{2}$ School of Biomedical Sciences, The Chinese University of Hong Kong, Hong Kong SAR, China. ${ }^{3}$ State Key Laboratory of Agrobiotechnology, The Chinese University of Hong Kong, Hong Kong SAR, China. ${ }^{4}$ Key Laboratory for Regenerative Medicine, Ministry of Education, The Chinese University of Hong Kong, Hong Kong SAR, China. Institute for Tissue Engineering and Regenerative Medicine, The Chinese University of Hong Kong, Hong Kong SAR, China.

\section{Received: 31 January 2021 Accepted: 22 March 2021}

\section{Published online: 03 May 2021}

\section{References}

1. Mond HG, Proclemer A. The 11th world survey of cardiac pacing and implantable cardioverter-defibrillators: calendar year 2009--a World Society of Arrhythmia's project. Pacing Clin Electrophysiol. 2011;34(8):1013-27. https://doi.org/10.1111/j.1540-8159.2011.03150.x.

2. Raatikainen MJP, Arnar DO, Merkely B, Nielsen JC, Hindricks G, Heidbuchel $H$, et al. A decade of information on the use of cardiac implantable electronic devices and interventional electrophysiological procedures in the European Society of Cardiology Countries: 2017 report from the European Heart Rhythm Association. Europace. 2017;19(suppl_2):ii1-ii90.

3. Greenspon AJ, Patel JD, Lau E, Ochoa JA, Frisch DR, Ho RT, Pavri BB, Kurtz SM. Trends in permanent pacemaker implantation in the United States from
1993 to 2009: increasing complexity of patients and procedures. J Am Coll Cardiol. 2012;60(16):1540-5. https://doi.org/10.1016/j.jacc.2012.07.017.

4. Eckhardt LL, Kalscheur MM. Replacing hardware with "Viralware". J Am Coll Cardiol. 2019;73(13):1688-90. https://doi.org/10.1016/j.jacc.2019.01.040.

5. Saito Y, Nakamura K, Ito H. Cell-based biological pacemakers: progress and problems. Acta Med Okayama. 2018;72(1):1-7. https://doi.org/10.18926/A $\mathrm{MO} / 55656$.

6. Ravindran D, Kok C, Farraha M, Selvakumar D, Clayton ZE, Kumar S, Chong J, Kizana E. Gene and cell therapy for cardiac arrhythmias. Clin Ther. 2020; 42(10):1911-22. https://doi.org/10.1016/j.clinthera.2020.09.001.

7. Lakatta EG, Maltsev VA, Vinogradova TM. A coupled SYSTEM of intracellular $\mathrm{Ca} 2+$ clocks and surface membrane voltage clocks controls the timekeeping mechanism of the heart's pacemaker. Circ Res. 2010;106(4): 659-73. https://doi.org/10.1161/CIRCRESAHA.109.206078.

8. Maltsev VA, Lakatta EG. Dynamic interactions of an intracellular Ca2+ clock and membrane ion channel clock underlie robust initiation and regulation of cardiac pacemaker function. Cardiovasc Res. 2008;77(2):274-84. https:// doi.org/10.1093/cvr/cvm058.

9. Maltsev VA, Lakatta EG. Synergism of coupled subsarcolemmal Ca2+ clocks and sarcolemmal voltage clocks confers robust and flexible pacemaker function in a novel pacemaker cell model. Am J Physiol Heart Circ Physiol. 2009;296(3):H594-615. https://doi.org/10.1152/ajpheart.01118.2008.

10. DiFrancesco D. Serious workings of the funny current. Prog Biophys Mol Biol. 2006;90(1-3):13-25. https://doi.org/10.1016/.jpbiomolbio.2005.05.001.

11. DiFrancesco D. The role of the funny current in pacemaker activity. Circ Res. 2010;106(3):434-46. https://doi.org/10.1161/CIRCRESAHA.109.208041.

12. Ju YK, Allen DG. Intracellular calcium and $\mathrm{Na}+-\mathrm{Ca} 2+$ exchange current in isolated toad pacemaker cells. J Physiol. 1998;508(Pt 1):153-66. https://doi. org/10.1111/j.1469-7793.1998.153br.x.

13. Zhou Z, Lipsius SL. $\mathrm{Na}(+)-\mathrm{Ca} 2+$ exchange current in latent pacemaker cells isolated from cat right atrium. J Physiol. 1993;466:263-85.

14. Sanders L, Rakovic S, Lowe M, Mattick PA, Terrar DA. Fundamental importance of $\mathrm{Na}+-\mathrm{Ca} 2+$ exchange for the pacemaking mechanism in guinea-pig sino-atrial node. J Physiol. 2006;571(Pt 3):639-49. https://doi. org/10.1113/jphysiol.2005.100305.

15. Bogdanov KY, Vinogradova TM, Lakatta EG. Sinoatrial nodal cell ryanodine receptor and $\mathrm{Na}(+)-\mathrm{Ca}(2+)$ exchanger: molecular partners in pacemaker regulation. Circ Res. 2001;88(12):1254-8. https://doi.org/10.11 61/hh1201.092095.

16. Okada T, Inoue R, Yamazaki K, Maeda A, Kurosaki T, Yamakuni T, Tanaka I, Shimizu S, Ikenaka K, Imoto K, Mori Y. Molecular and functional characterization of a novel mouse transient receptor potential protein homologue TRP7. $\mathrm{Ca}(2+)$-permeable cation channel that is constitutively activated and enhanced by stimulation of $\mathrm{G}$ protein-coupled receptor. J Biol Chem. 1999;274(39):27359-70. https://doi.org/10.1074/jbc.274.39.27359.

17. Zhang X, Spinelli AM, Masiello T, Trebak M. Transient receptor potential canonical 7 (TRPC7), a calcium (Ca(2+)) permeable non-selective cation channel. Adv Exp Med Biol. 2016;898:251-64. https://doi.org/10.1007/ 978-3-319-26974-0_11.

18. Liu X, Yao X, and Tsang S Y, Post-translational modification and natural mutation of TRPC channels. Cells. 2020; 9(1):135. https://doi.org/10.3390/ cells 9010135.

19. Alvarez J, Coulombe A, Cazorla O, Ugur M, Rauzier JM, Magyar J, Mathieu EL, Boulay G, Souto R, Bideaux P, Salazar G, Rassendren F, Lacampagne A, Fauconnier J, Vassort G. ATP/UTP activate cation-permeable channels with TRPC3/7 properties in rat cardiomyocytes. Am J Physiol Heart Circ Physiol. 2008;295(1):H21-8. https://doi.org/10.1152/ajpheart.00135.2008.

20. Satoh S, Tanaka H, Ueda Y, Oyama J, Sugano M, Sumimoto H, Mori Y, Makino $\mathrm{N}$. Transient receptor potential (TRP) protein 7 acts as a G protein-activated $\mathrm{Ca} 2+$ channel mediating angiotensin II-induced myocardial apoptosis. Mol Cell Biochem. 2007;294(1-2):205-15. https://doi.org/10.1007/s11010-006-9261-0.

21. Demion M, Bois P, Launay P, Guinamard R. TRPM4, a Ca2+-activated nonselective cation channel in mouse sino-atrial node cells. Cardiovasc Res. 2007;73(3):531-8. https://doi.org/10.1016/..cardiores.2006.11.023.

22. Hof T, Simard C, Rouet R, Salle L, Guinamard R. Implication of the TRPM4 nonselective cation channel in mammalian sinus rhythm. Heart Rhythm. 2013;10(11):1683-9. https://doi.org/10.1016/j.hrthm.2013.08.014.

23. Sah R, Mesirca P, Van den Boogert M, Rosen J, Mably J, Mangoni ME, et al. Ion channel-kinase TRPM7 is required for maintaining cardiac automaticity. Proc Natl Acad Sci U S A. 2013;110(32):E3037-46. https://doi.org/10.1073/ pnas. 1311865110 
24. Doleschal B, Primessnig U, Wolkart G, Wolf S, Schernthaner M, Lichtenegger M, Glasnov TN, Kappe CO, Mayer B, Antoons G, Heinzel F, Poteser M, Groschner K. TRPC3 contributes to regulation of cardiac contractility and arrhythmogenesis by dynamic interaction with NCX1. Cardiovasc Res. 2015; 106(1):163-73. https://doi.org/10.1093/cvr/cvv022.

25. Qi Z, Wong CK, Suen CH, Wang J, Long C, Sauer H, Yao X, Tsang SY. TRPC3 regulates the automaticity of embryonic stem cell-derived cardiomyocytes. Int J Cardiol. 2016;203:169-81. https://doi.org/10.1016/j.jicard.2015.10.018.

26. Maltsev VA, Wobus AM, Rohwedel J, Bader M, Hescheler J. Cardiomyocytes differentiated in vitro from embryonic stem cells developmentally express cardiac-specific genes and ionic currents. Circ Res. 1994;75(2):233-44. https://doi.org/10.1161/01.RES.75.2.233.

27. Hescheler J, Fleischmann BK, Lentini S, Maltsev VA, Rohwedel J, Wobus AM, et al. Embryonic stem cells: a model to study structural and functional properties in cardiomyogenesis. Cardiovasc Res. 1997;36(2):149-62. https:// doi.org/10.1016/S0008-6363(97)00193-4.

28. Lo IC, Chan HC, Qi Z, Ng KL, So C, Tsang SY. TRPV3 channel negatively regulates cell cycle progression and safeguards the pluripotency of embryonic stem cells. J Cell Physiol. 2016;231(2):403-13. https://doi.org/10.1002/jcp.25086.

29. Qi Z, Chen M, Song Y, Wang X, Li B, Chen ZF, Tsang SY, Cai Z. Acute exposure to triphenyl phosphate inhibits the proliferation and cardiac differentiation of mouse embryonic stem cells and zebrafish embryos. J Cell Physiol. 2019;234(11):21235-48. https://doi.org/10.1002/jcp.28729.

30. Chan HC, Lau YT, Ding Q, Li CK, Wong CM, Shaw PC, et al. PinX1t, a novel PinX1 transcript variant, positively regulates cardiogenesis of embryonic stem cells. J Am Heart Assoc. 2020;9(6):e010240.

31. Godar S, Ince TA, Bell GW, Feldser D, Donaher JL, Bergh J, Liu A, Miu K, Watnick RS, Reinhardt F, McAllister SS, Jacks T, Weinberg RA. Growth-inhibitory and tumor- suppressive functions of $\mathrm{p} 53$ depend on its repression of CD44 expression. Cell. 2008;134(1):62-73. https://doi.org/10.1016/j.cell.2008.06.006.

32. Picht E, Zima AV, Blatter LA, Bers DM. SparkMaster: automated calcium spark analysis with ImageJ. Am J Physiol Cell Physiol. 2007;293(3):C1073-81. https://doi.org/10.1152/ajpcell.00586.2006.

33. Miura Y, Kimura J. Sodium-calcium exchange current. Dependence on internal $\mathrm{Ca}$ and $\mathrm{Na}$ and competitive binding of external $\mathrm{Na}$ and $\mathrm{Ca}$. J Gen Physiol. 1989;93(6):1129-45. https://doi.org/10.1085/jgp.93.6.1129.

34. Qu Y, Whitaker GM, Hove-Madsen L, Tibbits GF, Accili EA. Hyperpolarizationactivated cyclic nucleotide-modulated 'HCN' channels confer regular and faster rhythmicity to beating mouse embryonic stem cells. J Physiol. 2008; 586(3):701-16. https://doi.org/10.1113/jphysiol.2007.144329.

35. Guo T, Zhang T, Mestril R, Bers DM. Ca2+/Calmodulin-dependent protein kinase II phosphorylation of ryanodine receptor does affect calcium sparks in mouse ventricular myocytes. Circ Res. 2006;99(4):398-406. https://doi. org/10.1161/01.RES.0000236756.06252.13.

36. Primeau JO, Armanious GP, Fisher ME, Young HS. The sarcoendoplasmic reticulum calcium ATPase. Subcell Biochem. 2018;87:229-58. https://doi. org/10.1007/978-981-10-7757-9_8.

37. Cheng H, Lederer WJ, Cannell MB. Calcium sparks: elementary events underlying excitation-contraction coupling in heart muscle. Science. 1993; 262(5134):740-4. https://doi.org/10.1126/science.8235594.

38. Vinogradova TM, Zhou YY, Maltsev V, Lyashkov A, Stern M, Lakatta EG. Rhythmic ryanodine receptor $\mathrm{Ca} 2+$ releases during diastolic depolarization of sinoatrial pacemaker cells do not require membrane depolarization. Circ Res. 2004;94(6):802-9. https://doi.org/10.1161/01.RES.0000122045.55331.0F.

39. Cleemann L, Wang W, Morad M. Two-dimensional confocal images of organization, density, and gating of focal Ca2+ release sites in rat cardiac myocytes. Proc Natl Acad Sci U S A. 1998;95(18):10984-9. https://doi.org/1 0.1073/pnas.95.18.10984

40. Lopez-Lopez JR, Shacklock PS, Balke CW, Wier WG. Local calcium transients triggered by single L-type calcium channel currents in cardiac cells. Science. 1995;268(5213):1042-5. https://doi.org/10.1126/science.7754383.

41. Sirenko S, Maltsev VA, Maltseva LA, Yang D, Lukyanenko Y, Vinogradova TM, Jones LR, Lakatta EG. Sarcoplasmic reticulum Ca2+ cycling protein phosphorylation in a physiologic $\mathrm{Ca} 2+$ milieu unleashes a high-power, rhythmic Ca2+ clock in ventricular myocytes: relevance to arrhythmias and bio-pacemaker design. J Mol Cell Cardiol. 2014;66:106-15. https://doi.org/1 0.1016/j.yjmcc.2013.11.011

\section{Publisher's Note}

Springer Nature remains neutral with regard to jurisdictional claims in published maps and institutional affiliations.

\section{Ready to submit your research? Choose BMC and benefit from:}

- fast, convenient online submission

- thorough peer review by experienced researchers in your field

- rapid publication on acceptance

- support for research data, including large and complex data types

- gold Open Access which fosters wider collaboration and increased citations

- maximum visibility for your research: over $100 \mathrm{M}$ website views per year

At $\mathrm{BMC}$, research is always in progress.

Learn more biomedcentral.com/submissions 